\title{
Skill Biased Technological and Organizational Change: Estimating a Mixed Simultaneous Equation Model Using the IAB Establishment Panel
}

\author{
Reinhard Hujer, Marco Caliendo and Dubravko Radić*
}

February 10, 2002

WORKING PAPER

\begin{abstract}
Recent years have brought growing evidence for an increasing labour demand for high skilled and a deterioration of the labour position of less skilled employees. The two most common explanations for this finding are an increasing international trade and a skill biased technological change. Another possible source for this phenomenon, that has received less attention in the recent discussion, are organizational changes that might affect labour demand in an asymmetric way, too.

This paper analyses the interdependencies between labour demand for high and low skilled employees, innovation activities and organizational changes. To this aim mixed simultaneous equation models are estimated using the IAB establishment dataset collected by the German Federal Employment Office.

Our empirical results indicate that technological change in the form of product innovations increases the demand for high and reduces the demand for low skilled employees. Organizational changes on the other hand do not have any significant effect on the labour demand, but are closely related to innovations.
\end{abstract}

Keywords: Mixed Simultaneous Equation Models, Labour Demand, Skill Biased Technological and Organizational Change.

JEL Classification: C35, D24, L23, O33.

${ }^{*}$ Reinhard Hujer is Professor of Statistics and Econometrics, Marco Caliendo and Dubravko Radić are Research Assistants at the Chair of Statistics and Econometrics, Johann Wolfgang Goethe-University of Frankfurt/M. Corresponding Author: Reinhard Hujer, Department of Economics and Business Administration, Chair of Statistics and Econometrics, Johann Wolfgang Goethe-University, Mertonstr. 17, 60054 Frankfurt/M., Germany, hujer@wiwi.uni-frankfurt.de. The authors thank Lutz Bellmann from the Institute for Employment Research ('Institut für Arbeitsmarkt- und Berufsforschung', IAB), Nürnberg for data support and Filiz Polat for research assistance. Financial support of the German Scientific Foundation ('Deutsche Forschungsgemeinschaft') is gratefully acknowledged. 


\section{CONTEnTs}

1. Introduction 3

2. Theoretical Considerations 4

2.1. Labour Demand . . . . . . . . . . . . . . . . . . . 4

2.2. Innovation Decision . . . . . . . . . . . . . . . . . 6

2.3. Organizational Changes . . . . . . . . . . . . . . 8

3. Econometric Modelling 9

3.1. Mixed Simultaneous Equation Models of Type I . . . . . . . . . . . . . . . 12

3.1.1. Identification . . . . . . . . . . . . . . . . 12

3.1.2. Estimation of Type I Models . . . . . . . . . . . . . . . . . . 13

3.2. Mixed Simultaneous Equation Models of Type II . . . . . . . . . . . . . . 14

3.2.1. Coherency Conditions for the Structural and Semireduced Form . 14

3.2.2. Estimation of Type II Models . . . . . . . . . . . . . . . . . . . . . 18

$\begin{array}{lr}\text { 4. Dataset and Descriptive Results } & 19\end{array}$

5. Estimation Results

6. Conclusions and Outlook 25

$\begin{array}{ll}\text { 7. Appendix } & 27\end{array}$ 


\section{INTRODUCTION}

The last 30 years have brought growing evidence for an increasing labour demand for high skilled and a deterioration of the labour market position of low skilled employees. In countries with a more flexible wage structure, like the United States and the United Kingdom, this increasing demand for high skilled employees manifests itself in a widening of the distribution of wages and an increasing income inequality. ${ }^{1}$

On the other hand, countries with more rigid wages, like most of the European countries, have to face increasing unemployment rates for unskilled workers. The European unemployment problem is thus seen to be caused by the same factors that are responsible for the increasing inequality of income in the U.S. and U.K. ${ }^{2}$

Economists offer three possible explanations for this phenomenon. One consists in an increasing international trade, often paraphrased with the notion of globalization. According to this view, an increasing inter-industry trade between the capital and skill abundant 'North' and the labour abundant 'South' will decrease the labour demand for low skilled employees in the northern countries. ${ }^{3}$

Another widespread explanation for an increased labour demand for high skilled employees is a skill biased technological change, i.e. a technological change which favours high skilled employees. According to this view, technological progress that manifests itself in increasing investments in information technology (IT) also increases the productivity of high skilled employees and therefore leads to a capital skill complementarity. Additionally, new products and processes are often more complex, therefore requiring a higher qualified staff. ${ }^{4}$

There is, however, a further explanation that has received less attention until now. Establishments recently introduced numerous organizational changes away from the traditional 'Taylorist' organization characterized by a centralization of authority. Examples include flattening of hierarchical levels or the introduction of more flexible and responsible workplaces. These organizational changes can be expected to require a higher level of human capital and therefore might be skill biased, too. ${ }^{5}$

The purpose of this paper is to analyse the interdependencies between labour demand for high and low skilled employees, innovation activities and organizational changes. To meet this aim we will use the 1998 wave of the IAB establishment panel, a large panel dataset collected by the German Federal Employment Office ('Bundesanstalt für Arbeit') which focuses on the demand side situation of the labour market.

The 1998 wave allows us to distinguish between different qualification groups: Blue and white collar employees for simple and qualified jobs. Additionally it contains information about radical and incremental product innovations and organizational changes introduced by the establishments like the ones mentioned above.

Since some of the considered variables are qualitative, we have to utilize a mixed simultaneous equation model. Thereby two different approaches can be distinguished: Type I models which are defined in terms of the latent variables and type II models with endogenous dummy variables appearing as additional explanatory variables. The

\footnotetext{
${ }^{1}$ See e.g. Snower (1999).

${ }^{2}$ Or using the words of Krugman (1994): 'The European unemployment problem and the US inequality problem are two sides of the same coin.'

${ }^{3}$ See Berman and Griliches (1994) and Berman, Bound, and Machin (1998), who have conducted shift share-analysis for the U.S. and OECD economies, and Falk and Seim (1999), who have done the same for the German service sector.

${ }^{4}$ See Bartel and Lichtenberg (1987), Krueger (1993), Autor, Katz, and Krueger (1998).

${ }^{5}$ See Crepon, Duguet, and Mairesse (1998), Bresnahan, Brynjolfsson, and Hitt (1999) or Caroli and Reenen (2001).
} 
structural form parameters of type II models have to fulfill additional restrictions to ensure the coherency of this model. We will apply both models and pay special attention to the consequences arising from the parameter restrictions for type II models.

The subsequent considerations proceed as follows: In the second section we will present some theoretical considerations about the determinants of labour demand, innovation activities and organizational changes. Section three of this paper deals with the econometric specification and estimation of mixed simultaneous equation models. Section four introduces the IAB establishment panel and presents first descriptive evidence while section five presents the estimation results. Finally, some concluding remarks are given in section six.

\section{Theoretical Considerations}

The aim of this section is to give a brief overview of the theoretical expected determinants of labour demand, innovation decisions and organizational changes. Having identified potential explanatory variables and functional forms, we will consider the appropriate econometric modelling in the next section.

\subsection{Labour Demand}

In this section we will derive factor demand equations by starting from the following general cost function ${ }^{6}$

$$
C=f\left(w_{\text {high }}, w_{\text {low }}, w_{\text {app }}, K, Y\right)
$$

where

$$
\begin{aligned}
C & =\text { Total cost } \\
w_{\text {high }} & =\text { Wage rate for high skilled employees } \\
w_{\text {low }} & =\text { Wage rate for low skilled employees } \\
w_{\text {app }} & =\text { Wage rate for apprentices } \\
K & =\text { Capital stock } \\
Y & =\text { Output. }
\end{aligned}
$$

We assume that there are three variable input factors, namely employees with high and low education, respectively $L_{h i g h}$ and $L_{l o w}$, apprentices, $L_{a p p}$, and one quasi fixed input factor, which is capital stock in 1998, $K$. The group of high skilled employees thereby consists of skilled workers and white collar workers for qualified tasks, whereas low skilled employees include un- and semiskilled blue collar and white collar workers as well as officials for simple tasks.

If we define $Z$ as a column vector consisting of $K$ and $Y$, (1) can also be written more conveniently as

$$
C=f\left(w_{\text {high }}, w_{\text {low }}, w_{\text {app }}, Z\right) .
$$

There are several cost functions which can be used to approximate (1). ${ }^{7}$ The most

\footnotetext{
${ }^{6}$ See Bartel and Lichtenberg (1987).

${ }^{7}$ See e.g. Hamermesh $(1986,1993)$.
} 
flexible is the translog cost function leading to the following specification

$$
\begin{aligned}
\ln C= & \ln \alpha_{0}+\sum_{i \in I} \alpha_{i} \ln w_{i}+\frac{1}{2} \sum_{i \in I} \sum_{j \in I} \alpha_{i j} \ln w_{i} \ln w_{j} \\
& +\sum_{i=1}^{2} \beta_{i} \ln Z_{i}+\frac{1}{2} \sum_{i=1}^{2} \sum_{j=1}^{2} \beta_{i j} \ln Z_{i} \ln Z_{j} \\
& +\frac{1}{2} \sum_{i \in I} \sum_{j=1}^{2} \gamma_{i j} \ln w_{i} \ln Z_{j}
\end{aligned}
$$

with $I=\{$ high,low,app $\}, \alpha_{i j}=\alpha_{j i}, \beta_{i j}=\beta_{j i}$ and $\gamma_{i j}=\gamma_{j i}$. For (3) to be homogenous of degree 1 in prices, the following restrictions have to be imposed:

$$
\sum_{i} \alpha_{i}=1 \text { and } \sum_{i} \alpha_{i j}=\sum_{j} \alpha_{j i}=\sum_{i} \gamma_{i j}=0
$$

Differentiating (3) with respect to the factor prices and applying Shephard's lemma

$$
\frac{\partial \ln C}{\partial \ln w_{i}}=\frac{w_{i} L_{i}}{C}=S_{i} \quad \text { for } i=h i g h, \text { low and } a p p
$$

yields the following cost share equations

$$
S_{i}=\alpha_{i}+\frac{1}{2} \sum_{j \in I} \alpha_{i j} \ln w_{j}+\frac{1}{2} \sum_{j=1}^{2} \gamma_{i j} \ln Z_{j}
$$

for $i=h i g h$,low and app. Since the three share equations sum up to one, we will skip the share equation for apprentices in the following. Imposing the restrictions in (4) we arrive at the following factor demand equations

$$
\begin{array}{r}
S_{\text {high }}=\alpha_{\text {high }}+\sum_{i \in\{\text { high }, \text { low }\}} \alpha_{\text {high }, i} \ln \frac{w_{\text {high }}}{w_{\text {app }}}+\gamma_{\text {high }, i} \ln \frac{K}{Y} \\
S_{\text {low }}=\alpha_{\text {low }}+\sum_{i \in\{\text { high }, \text { low }\}} \alpha_{\text {low }, i} \ln \frac{w_{\text {low }}}{w_{\text {app }}}+\gamma_{\text {low }, i} \ln \frac{K}{Y} .
\end{array}
$$

Since our dataset does not contain any information about wages for different skill groups, we will approximate the cost share for the $i$-th skill group with their employment share. ${ }^{8}$ Furthermore assuming that the relative wages $\frac{w_{i}}{w_{a p p}}$ will not vary across industries, we can capture this effect using industry dummies. The physical capital stock will be approximated by the investments of the last year.

These theoretically founded employment share equations will be used further on for the empirical implementation. Additionally to the industry dummies we will also include other control variables that might affect the labour demand. Possible candidates are the business development of the past year, investments in communication and information technology, competition pressure, state of technology and regional dummies. Since our main interest lies in the employment effects of product innovations and organizational changes, corresponding dummy variables will also be taken into account. Table A.I in the appendix contains a description of the variables used in the analysis.

Since we have not included factor prices in the equations, no symmetry or other restrictions have to be considered and hence the augmented versions of (6) and (7) could

\footnotetext{
${ }^{8}$ See e.g. Berman and Griliches (1994) or Falk and Seim (1999) who proceed in the same manner.
} 
be estimated separately using OLS. Table A.IV and A.V in the appendix contain the so obtained estimation results for high and low skilled employees. We will discuss these in section five.

One of the main problems with this proceeding, however, is the potential endogeneity of the innovation and organizational change dummies in the labour demand equations. Introduced product innovations and organizational changes clearly depend on a number of decisions made by the establishments and therefore should be modelled in a simultaneous equation framework. In the next two sections we will discuss possible determinants of innovation decisions and organizational changes in greater detail before turning to the problem of simultaneity. We will then compare the estimation results obtained by applying OLS separately to (6) and (7) with more appropriate methods which take a possible simultaneous bias into account.

\subsection{Innovation Decision}

Technological change can be roughly divided into process and product innovations (see also figure 1). ${ }^{9}$ The first refers to any changes that enable establishments to produce a given output at lower costs, while the latter means the introduction of new products and services. Process innovation can be further distinguished as to whether it comes along with investments in new capital goods (embodied process innovation), e.g. investments in information and communication technology, or it reflects an increase in the production efficiency (disembodied process innovation).

Product innovation can be categorized into improvement of existing products and the introduction of products that are new for the establishment (incremental product innovation) or new for the market (radical product innovation).

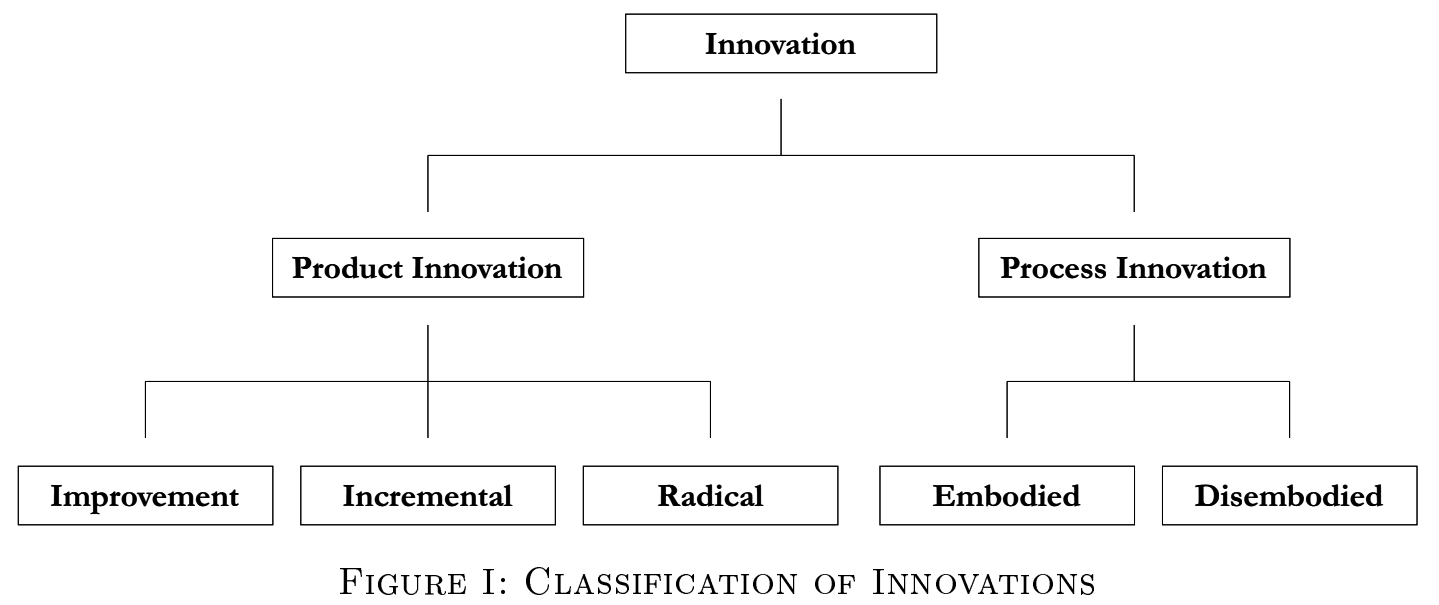

It is widely believed that product innovations, in opposition to process innovations, have a positive employment effect. Especially for radical product innovations, i.e. products which are not close substitutes to existing ones, Katsoulacos (1986) has shown that the positive welfare effect which stems from the increase of the workers' utility from consumption leads to an increase in the total employment. The theoretical literature is, however, relatively scarce with regard to the employment effects for different qualification groups of employees. This theoretical ambiguity makes an empirical assessment necessary.

Our dataset allows us to distinguish between these various forms of product innovations introduced by the establishments during the years 1996 and 1997: Improvement,

${ }^{9}$ See Katsoulacos (1986). 
incremental and radical. Since there are high positive correlations between them (see the next section for some descriptive results), we will combine them to one single dummy variable, INNO, which equals one if at least one of the innovation forms is realized and zero otherwise.

Embodied process innovations are in part captured by the total net investments, especially investments in information and communication technology, ICT. Our dataset, however, allows us a much broader view of process innovation. While the use of computers has been in the center of the debate about the employment consequences of technological change, it has been recognized recently that exploiting full advantage from computerization requires a redesign of the organization of workplaces, too. Technological change and changes in the organizational structure of workplaces are closely related. ${ }^{10}$ We will take this into account by explicitly considering organizational changes as an integral part of disembodied process innovations.

With regard to the product innovation decision, we assume a latent threshold model

$$
I N N O= \begin{cases}1 & \text { if } I N N O^{*} \geq 0 \\ 0 & \text { otherwise }\end{cases}
$$

where $I N N O^{*}$ can be interpreted as the propensity of an establishment to innovate, depending linearly on a set of explanatory variables, i.e. $I N N O^{*}=\beta_{\text {inno }}^{\prime} x_{\text {inno }}+u_{\text {inno }}$. For the error term we assume $u_{\text {inno }} \sim \operatorname{IIN} D\left(0, \sigma_{\text {inno }}\right)$. In the following we will discuss some potential determinants of the innovation decision. Thereby a distinction in firm specific and market specific characteristics proves to be useful.

Firm specific factors include factors like the qualification structure of employees. The human factor is without doubt one of the major factors for the innovation propensity of establishments. We will make use of the following indicator to measure the human capital of an establishment: Share of high qualified white and blue collar employees in 1996. Additionally, we will take into account whether establishments possess departments for both research and development (R\&D) and marketing research, respectively. One might also think that certain organizational environments like e.g. flatter and flexible hierarchies, are more beneficial for innovation activities than others. We will test this hypothesis by including an appropriate dummy variable in the innovation equation. Another possible determinant which will be taken into account is the effect of profit participation plans for employees.

Establishments that do not execute $R \& D$ themselves can capture positive spill-over effects by cooperating with other institutions, e.g. customers, suppliers, competitors or universities. We will take this possibility into account by including the dummy variable $C O O P$ which equals one, if an establishment is engaged in a $\mathrm{R} \& \mathrm{D}$ cooperation with one of these institutions. Additionally, we will consider the total investments in 1997 as a proxy for the capital stock, investments in information and communication technology in 1995 and the state of the technology in 1996 as other possible factors for the innovation activities.

Possible push factors coming from the market side will be captured by the business development for the year 1997 and the competition pressure perceived by the establishments in 1998. Unfortunately, our dataset does not contain any other information about the market structure, e.g. market power and diversification of single establishments or industrial concentration.

Size of the establishment, which is traditionally considered as another important determinant of innovation activities, will be taken into account using dummy variables for different size classes. In addition industry and regional dummies as well as the legal

${ }^{10}$ See e.g. Bell (1996) and Bresnahan, Brynjolfsson, and Hitt (1999). 
form of the establishment will also be included. Table A.II in the appendix contains a detailed description of the variables used in the analysis.

Again one obvious idea would be to estimate equation (8) directly using standard maximum likelihood methods. The major drawback of this proceeding, however, consists in a potential endogeneity bias. Table A.VI in the appendix contains the standard ML-estimation results in the column labelled ML. In section five these results will be contrasted to those obtained by using more appropriate econometric models which take the potential endogeneity of the dummy regressors into account.

\subsection{Organizational Changes}

It is nowadays generally accepted that establishments with a higher degree of functional flexibility are in a better position to react and adapt promptly to changing economic conditions and new opportunities. This flexibility is especially necessary in an economic environment with increasing competition and pressure to adjust to changing circumstances. ${ }^{11}$

In this context establishments have experienced dramatic changes in their organizational structure over the past decades. ${ }^{12}$ Recent changes are characterized by a trend away from a centralized, so called 'Taylorist' organization. Instead, more and more establishments introduced decentralized and flexible workplaces with more responsibilities for the individual worker and fewer hierarchical levels.

Clearly there are complementarities between the internal organization of an establishment and the above mentioned embodied process innovations, like e.g. investments in ICT. ${ }^{13}$ Better communication possibilities associated with ICT also require appropriate organizational changes to fully exploit the advantages of computerization. In this sense technological change and changes in the organizational structure of workplaces are closely related. Similarly, product innovations might have an impact on introduced organizational changes, too.

In the following we will consider whether establishments have undertaken one of the following organizational changes during the years 1996 and 1997:

- Reorganization of departments and functional areas,

- decentralization of responsibilities and decision-authority,

- introduction of group-workplaces with own responsibilities or

- introduction of units with own costing and result calculation.

Since there are high positive correlations between these changes (see the next section for some descriptive results), we will combine them to one single dummy variable, $O R G A$, which equals one if at least one of the organizational changes is realized and zero otherwise.

Before the introduction, establishments will weigh up the cost-benefit ratio arising from organizational changes. The benefits are due to flatter hierarchies and include a reduction in a variety of cost categories, especially communication and information costs. With fewer hierarchical levels, the coordination and monitoring costs can be expected to decrease, too. Since workplaces with more tasks and responsibilities offer employees more job satisfaction, productivity gains can arise.

There are, however, costs which have to be considered and which consist mainly in a higher risk of duplication of information due to a lack of centralization, an increase

\footnotetext{
${ }^{11}$ Lundvall and Kristensen (1997).

${ }^{12}$ See e.g. Caroli and Reenen (2001).

${ }^{13}$ See Bresnahan, Brynjolfsson, and Hitt (1999).
} 
of mistakes due to a lack of monitoring and decreasing returns to scale due to a lower specialization.

The costs and benefits associated with more decentralized and flexible organizations depend on a number of factors. One obvious assumption is that the trade-off between costs and benefits of organizational changes improves with an increasing qualification structure of the employees. More qualified employees are more able to analyse the growing information flood caused by flatter hierarchies and to exploit the scope offered by workplaces with more responsibilities. Thus we expect establishments with a higher qualified staff to have a higher propensity to introduce organizational changes and vice versa.

Another main factor that might have a positive impact on the introduction of organizational changes is a growing competition pressure since it increases the gains of flexibility and decentralization. We will capture this effect using assessments of the establishments regarding the competition pressure as well as the business development.

We have already mentioned the expected complementarities between embodied process innovations as measured by investments in ICT and organizational changes. Additional explanatory variables, which will be taken into account, therefore consist of investments, especially in ICT. To consider possible effects of product innovations on the propensity to introduce organizational changes, we will also include the dummy variable INNO.

To capture other firm characteristics, industrial and regional as well as size dummies will also be included. Machin and Wadhwani (1991) pointed out that unions might have an impact on the introduction of organizational changes. We will therefore include an appropriate dummy variable as well as variables indicating the legal form of the establishment. Table A.III in the appendix contains a description of the variables used for estimating the following organizational change equation

$$
O R G A= \begin{cases}1 & \text { if } O R G A^{*}=\beta_{\text {orga }}^{\prime} x_{\text {orga }}+u_{\text {orga }} \geq 0 \\ 0 & \text { otherwise }\end{cases}
$$

with $u_{\text {orga }} \sim \operatorname{IIND}\left(0, \sigma_{\text {orga }}\right)$.

Table A.VII in the appendix contains the estimation results obtained by employing standard ML-estimation methods in the column labelled ML. ${ }^{14}$ In the following we will examine if these results deviate from the estimation results obtained from a mixed simultaneous equation model.

\section{ECONOMEtric Modelling}

Collecting the equations for the share of high and low skilled employees, innovation decision and introduced organizational changes, yields the following simultaneous equation model

$$
\begin{gathered}
S_{\text {high }}=\gamma_{13} I N N O+\gamma_{14} \text { ORGA }+\beta_{\text {high }}^{\prime} x_{\text {high }}+u_{\text {high }} \\
S_{\text {low }}=\gamma_{23} I N N O+\gamma_{24} \text { ORGA }+\beta_{\text {low }}^{\prime} x_{\text {low }}+u_{\text {low }} \\
\text { INNO* }=\gamma_{34} \text { ORGA+ } \beta_{\text {inno }}^{\prime} x_{\text {inno }}+u_{\text {inno }} \\
\text { ORGA } A^{*}=\gamma_{43} I N N O+\beta_{\text {orga }}^{\prime} x_{\text {orga }}+u_{\text {orga }}
\end{gathered}
$$

${ }^{14}$ Section five will go further into detail concerning the interpretation of the estimation results. 
where the observable dummy variables are linked with their latent counterpart via the following threshold models

$$
I N N O=\left\{\begin{array}{ll}
1 & \text { if } I N N O^{*} \geq 0 \\
0 & \text { otherwise }
\end{array} \text { and } O R G A= \begin{cases}1 & \text { if } O R G A^{*} \geq 0 \\
0 & \text { otherwise. }\end{cases}\right.
$$

Since some of the endogenous explanatory variables are qualitative, models like the one in (10) - (14) are called mixed simultaneous equation models.

Classical simultaneous equation models in which all encountered variables are continuous are well known to econometricians and have been successfully applied to a variety of problems, mainly macroeconomic ones involving longitudinal data sets.

However, the rapid growth and availability of microeconomic data sets have recently also raised the interest in discrete data and appropriate econometric models since individual decisions and choices reflected in such data sets are often not made over a continuum but over a limited number of possibilities and alternatives.

Another already mentioned problem besides the qualitative nature of some variables is due to the fact that some explanatory variables are the outcome of other decisions by the individuals and therefore have to be modelled simultaneously.

Mixed simultaneous econometric models (MSEM) can be used when working with data sets involving both quantitative and qualitative jointly dependent variables. The field of applications is broad ranging from consumer analysis, labour economics to questions coming from financial analysis. Since MSEM might be computational demanding and feature additional identification, consistency and coherency problems, the applications are rather scarce. ${ }^{15}$

By modelling a simultaneous model with endogenous dummy, ordered and/or truncated variables, two different approaches can be distinguished: ${ }^{16}$

- Type I Models: Latent variable formulation or

- Type II Models: Dummy variable formulation.

Type I models are basically simultaneous equation models defined in terms of the underlying latent variables. Let $y_{i}^{*}$ be a $(G \times 1)$ vector which contains the latent variables for the $i$-th individual, $x_{i}$ a $(K \times 1)$ vector with explanatory variables, $u_{i}$ a $(G \times 1)$ vector with stochastic disturbances, $\Gamma$ a $(G \times G)$ and $B$ a $(G \times K)$ matrix containing the structural form parameters.

A mixed simultaneous type I model can then be written as

$$
\Gamma^{*} y_{i}^{*}+B x_{i}=u_{i}
$$

Since (15) corresponds to a standard simultaneous equation model defined in terms of $y_{i}^{*}$, an explicit and unique reduced form for (15) exists which can be used to estimate the reduced form parameters. The only additional problem which arises is due to the

\footnotetext{
${ }^{15}$ Some examples are Lee (1978) and Schmidt (1978): Analysis of the impact of labour unions on wage rates of workers, Nelson and Olson (1978): Analyzing the determinants of decisions about post secondary vocational school training, Waldman (1981): Analyzing the interrelation between work, leisure and schooling time decision, Ransom (1987): Analyzing family labour supply and consumption decision, Pohlmeier (1989): Analysis of market structure and innovation activities, Browning (1992): Children and household economic behavior, Blundell and Smith (1993): Joint decision model for married women's hours of work and household income and $\mathrm{Li}$ (1998): Joint determination of a financially distressed high yield company's length of time in default and its likelihood of seeking bankruptcy protection.

${ }^{16}$ E.g. Blundell and Smith $(1993,1994)$. Besides type I and type II models so called log-linear models have been proposed in the literature. Since these models, however, can not be interpreted in a structural manner, we will not consider them here. For a detailed discussion see e.g. Maddala (1983) or Hamerle and Tutz (1996).
} 
fact that not all of the endogenous variables are directly observable thus making some additional identification conditions necessary.

Whereas type I models are defined in terms of the latent variables, mixed simultaneous type II models might also contain the observable dependent variables as regressors. Using the notation above, type II models can be written as

$$
\Gamma^{*} y_{i}^{*}+\Gamma y_{i}+B x_{i}=u_{i}
$$

Since in (16) not only $y_{i}^{*}$ but also $y_{i}$ appears, no explicit reduced form for this model exists. Additional to the identification criterion, the structural form parameters in (16) have to fulfill the so called coherency condition which ensures that for every admissible value of $x_{i}, u_{i}, B, \Gamma^{*}$, and $\Gamma$ a unique value of $y_{i}$ is associated.

This coherency condition must be distinguished from the identification condition. ${ }^{17}$ The former ensures the existence and uniqueness of the reduced form whereas the latter ensures the uniqueness of the parameters of the structural form. Identification therefore presupposes the coherency of a model.

At this point it should be stated that type I and type II models are nonnested alternatives. This follows from the fact that simply setting $\Gamma$ equal to zero in (16) does not yield a type I model since type II models require additional parameter restrictions due to the coherency problem. ${ }^{18}$

The decision when to apply which model should be guided by economic considerations. In type I models, individual behavior is completely described by the latent variables and the censoring process simply acts as a constraint on the information available to the econometrician whereas for type II models the observability rule also constraints the agent's set of choices.

Bresnahan and Smith (1993) consider a model describing household labour supply and consumption behaviour. If the hours of work are only observable in grouped form, e.g. full and part time, although the individual has the choice over a scope of hours of work, the appropriate model would be a type I model. In this case consumption would be a function of the underlying latent hours of work and not of the observable hours of work.

If on the other hand individuals only have the choice between full and part time work, not the latent but the observable dummy variable would have an impact on the consumption decision of households and thus a type II model would be appropriate.

Type II models are equivalent to the so called hybrid model with structural shift proposed by Heckman (1978). In this model both the latent and the observable endogenous variable appear as regressors in one equation. Another special case of type II models are switching regression models described in Gourieroux, Laffont and Monfort (1980).

Since in our empirical case of the employment effects of innovations and organizational changes there are no clear theoretical suggestions whether only the actual observable decisions have an impact on other variables, as in the above formulated model (10) (14), or also the latent propensity to innovate or introduce organizational changes, in the following we will estimate both models and test which one is appropriate. In the next two subsections we will take a closer look at both of them.

\footnotetext{
${ }^{17}$ See e.g. Gourieroux, Laffont and Monfort (1980)

${ }^{18}$ See Blundell and Smith (1993).
} 


\subsection{Mixed Simultaneous Equation Models of Type I}

\subsubsection{Identification}

Let us write down the structural form of the type I mixed simultaneous equation model using matrix notation

$$
\Gamma^{*} y_{i}^{*}+B x_{i}=u_{i}
$$

where

$\Gamma^{*}=\left(\begin{array}{cccc}1 & 0 & -\gamma_{13} & -\gamma_{14} \\ 0 & 1 & -\gamma_{23} & -\gamma_{24} \\ 0 & 0 & 1 & -\gamma_{34} \\ 0 & 0 & -\gamma_{43} & 1\end{array}\right), \quad y_{i}^{*}=\left(\begin{array}{c}S_{\text {high }} \\ S_{\text {low }} \\ I N N O^{*} \\ O R G A^{*}\end{array}\right)_{i}, \quad B=\left(\begin{array}{c}-\beta_{\text {high }} \\ -\beta_{\text {low }} \\ -\beta_{\text {inno }} \\ -\beta_{\text {orga }}\end{array}\right), \quad u_{i}=\left(\begin{array}{c}u_{\text {high }} \\ u_{\text {low }} \\ u_{\text {inno }} \\ u_{\text {orga }}\end{array}\right)_{i}$,

$x_{i}$ is a $(K \times 1)$ vector containing all exogenous variables and the $\beta$ 's are $(1 \times K)$ vectors containing the structural form parameters. For the vector $u_{i}$ it is assumed that $E\left(u_{i}\right)=$ $0, \forall i=1, \ldots, N$ and that there are no correlations between different individuals, i.e. $E\left(u_{i} u_{j}\right)=0, \forall i \neq j$. The variance covariance matrix of the structural form residual for the $i$-th individual is given by $E\left(u_{i} u_{i}^{\prime}\right)=\Sigma$.

The dependency structure between the jointly endogenous variables can be summarized as in figure II. We assume that the propensities to innovate and to introduce organizational changes during the years 1996 and 1997 might have an impact on the labour demand for high and low skilled employees in 1998, whereas the innovation decision and the decision to introduce organizational changes are not affected by the actual employment situation but the situation prevailing in 1996. On the other hand, we allow simultaneous relations between the propensity to innovate and the propensity to introduce organizational changes.

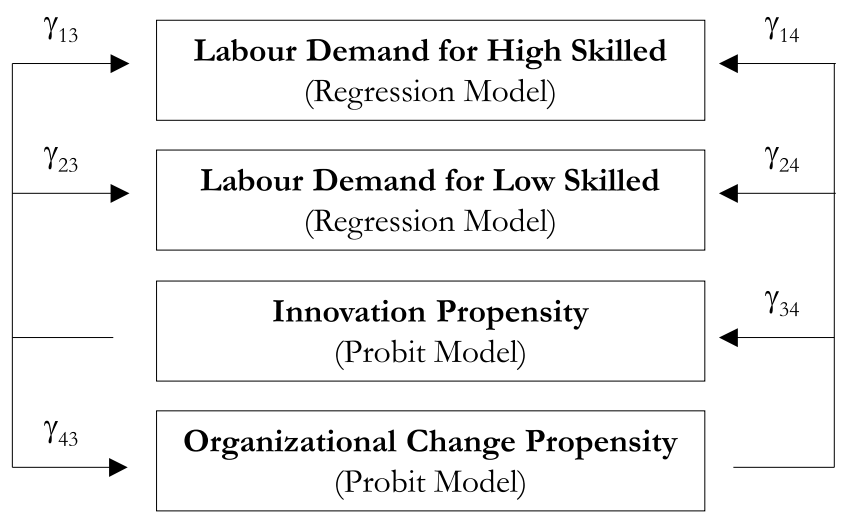

Figure II: Type I Dependency Structure and Econometric Models

The model in (17) represents a classical simultaneous equation model defined in terms of the latent variables. Therefore the usual identification problems arise which are solved by excluding from every equation at least as much exogenous variables as the number of included endogenous variables, i.e. imposing a number of zero restrictions on the $(1 \times K)$ vectors $\beta_{\text {high }}, \beta_{\text {low }}, \beta_{\text {inno }}$ and $\beta_{\text {orga }}$.

However, identification problems arise not only due to the fact that the number of structural form parameters exceeds the reduced form parameters. Since some of the latent variables are not observable, additional identification problems arise even for the 
reduced form parameters of the two Probit equations. To demonstrate this let us first of all derive the reduced form of (17)

$$
y_{i}^{*}=\Pi x_{i}+v_{i}
$$

with

$$
\Pi \equiv-\Gamma^{*-1} B, \quad v_{i} \equiv \Gamma^{*-1} u_{i} \quad \text { and } \quad E\left(v_{i} v_{i}^{\prime}\right)=\Omega .
$$

The parameters of the structural form are hence linked with the parameters of the reduced form via the following equation

$$
\Gamma^{*} \Pi+B=0 .
$$

Assuming that the usual identification criteria are met, the reduced form parameters of the first two regression equations are exactly identified whereas the reduced form parameters of the Probit equations are only estimable up to a scaling parameter $1 / \lambda_{g}$ with $\lambda_{g}$ being the variance of the $g$-th reduced form Probit equation. The same holds true for the covariance of the reduced form residuals between two equations involving at least one Probit equation which is also identified only up to a scaling parameter $1 / \lambda_{g}$.

Due to the fact that not all variables are directly observable, the structural form parameters are also only identified up to a scaling parameter. In order to identify them, in the following we will restrict the variances of the Probit equations to one, i.e. set $\lambda_{g}=1$ for the $g$-th reduced form Probit equation.

\subsubsection{Estimation of Type I Models}

We now turn to the question of how to estimate the parameters of a MSEM of type I. Two approaches can be distinguished: System estimation and single equation estimation procedures.

System estimation procedures are full information procedures using all information contained in the different equations. They are computationally more burdensome since they require the evaluation of a $n$-fold integral in the case of a MSEM with $n$ Probit equations.

This problem can be avoided by the use of single equation estimation procedures which are in fact two stage estimators. In a first step the parameters of the reduced form are estimated by means of standard methods. The so obtained parameters are then used in a second step to estimate the parameters of the structural form.

There are several procedures which were proposed in this context. ${ }^{19}$ We will apply the two most common ones, namely the two stage estimators proposed by Amemiya $(1974,1979)$ and Nelson and Olson (1978).

The Amemiya Estimation Procedure Amemiya $(1978,1979)$ suggests after estimating the reduced form parameters in $\Pi$ by standard methods, to use equation (20) to estimate the structural form parameters. With $\Gamma_{g}$ and $B_{g}$ as the $g$-th row of $\Gamma$ and $B$ respectively, for the $g$-th equation we have

$$
\Gamma_{g} \Pi=B_{g} .
$$

We further define:

\footnotetext{
${ }^{19}$ See Blundell and Smith $(1993,1994)$ for an overview and Lee (1990) for a discussion of the asymptotic properties of different estimation methods.
} 
$\gamma_{g} \quad(1 \times r)$ row vector of $\Gamma_{g}$ which contains the parameters of the $r$ endogenous variables included in the $g$-th equation,

$\beta_{g} \quad(1 \times s)$ row vector of $B_{g}$ which contains the parameters of the $s$ exogenous variables included in the $g$-th structural form equation,

$\pi_{g}(1 \times K)$ row vector which contains the reduced form parameters of the $K$ exogenous variables in the $g$-th reduced form equation,

$\underline{\Pi}_{g} \quad$ submatrix of $\Pi$ containing the parameters to be multiplied with $\gamma_{g}$ and

$J_{g}$ selection matrix such that $J_{g} \beta_{g}^{\prime}=B_{g}^{\prime}$.

After transposing, equation (21) can be written as

$$
\pi_{g}^{\prime}=\underline{\Pi}_{g}^{\prime} \gamma_{g}^{\prime}+J_{g} \beta_{g}^{\prime} .
$$

The structural form parameters of the $g$-th equation can then be estimated by substituting the $\pi$-parameters in (22) by their first step estimates $\hat{\pi}$ and computing the OLS or GLS estimators for $\gamma_{g}^{\prime}$ and $\beta_{g}^{\prime}$.

The Nelson-Olson Estimation Procedure Nelson and Olson (1978) suggest to estimate in a first step the reduced form parameters by standard methods. These parameters can be used to get predictions for the latent variables according to

$$
\hat{y}_{i}^{*}=\hat{\Pi} x_{i} .
$$

In a second step the predicted values for $y_{i}^{*}$ are used to obtain the parameters of the structural form by inserting the $\hat{y}_{i}^{*}$ into the structural form equations and applying standard estimation methods to obtain estimates for $\Gamma$ and $B$.

\subsection{Mixed Simultaneous Equation Models of Type II}

\subsubsection{Coherency Conditions for the Structural and Semireduced Form}

For the following considerations we will use the notation introduced in section 3.1. A mixed simultaneous type II model for the $i$-th individual can then be written as

$$
\Gamma^{*} y_{i}^{*}+\Gamma y_{i}+B x_{i}=u_{i}
$$

In contrast to type I models we permit that not only the latent variables contained in $y_{i}^{*}$ are considered in the structural model but also some of their observable counterparts in $y_{i}$. One consequence of this inclusion is the nonexistence of an explicit reduced form. By premultiplying (24) with the inverse of $\Gamma^{*}$, however, a semireduced form can be derived

$$
y_{i}^{*}=\widetilde{\Gamma} y_{i}+\widetilde{B} x_{i}+\widetilde{u}_{i}
$$

with $\widetilde{\Gamma}=-\Gamma^{*^{-1}} \Gamma, \widetilde{B}=-\Gamma^{*^{-1}} B$ and $\widetilde{u}_{i}=\Gamma^{*^{-1}} u_{i}$.

In order to ensure that for every admissible value of $\Gamma^{*}, \Gamma, B, x$ and $u$ a unique value for $y$ is associated, the structural form parameters in (24) have to fulfill certain restrictions. Such restrictions are called coherency or consistency conditions.

In the following we will demonstrate the coherency problem associated with type II models using a two equation Probit model before generalizing the results to the $n$ 


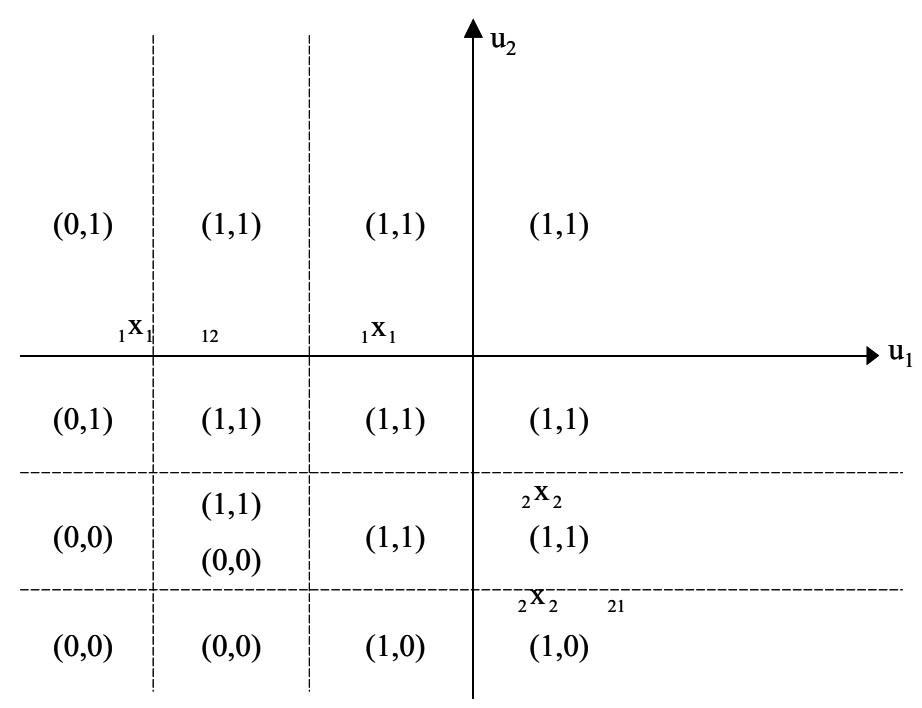

Figure III: Simultaneous Probit Model with Multiple Equilibria

equation case. ${ }^{20}$ Skipping the index $i$ for convenience and using the indicator function $I(\cdot)$ which equals one if $\cdot$ holds true and zero otherwise, we arrive at

$$
\begin{aligned}
y_{1}^{*} & =\beta_{1} x_{1}+\gamma_{12} y_{2}+u_{1} \\
y_{2}^{*} & =\beta_{2} x_{2}+\gamma_{21} y_{1}+u_{2} \\
y_{i} & =I\left(y_{i}^{*}\right) \quad i=1,2 .
\end{aligned}
$$

Let us suppose that $\gamma_{12}$ and $\gamma_{21}$ are both positive. ${ }^{21}$ The correspondence between the latent and observable variables can be depicted using figure III.

If e.g. $u_{1}$ is greater than $-\beta_{1} x_{1}$ then $y_{1}$ will equal one regardless of the value of $y_{2}$. The same holds if $u_{2}$ is greater than $-\beta_{2} x_{2}$ for $y_{2}$ so that for all $\left(u_{1}, u_{2}\right) \in\left(-\beta_{1} x_{1}, \infty\right) \times$ $\left(-\beta_{2} x_{2}, \infty\right)$ the corresponding value for the observable endogenous variables is $(1,1)$. In the same manner a unique relationship between $\left(u_{1}, u_{2}\right)$ and $\left(y_{1}, y_{2}\right)$ can be derived for the other regions, except for the area $\left(u_{1}, u_{2}\right) \in\left(-\beta_{1} x_{1}-\gamma_{12},-\beta_{1} x_{1}\right) \times\left(-\beta_{2} x_{2}-\gamma_{21},-\beta_{2} x_{2}\right)$.

To show why for this $\left(u_{1}, u_{2}\right)$ combination multiple equilibria arise, assume that $y_{2}$ equals zero. Then $y_{1}$ also equals zero since every $u_{1}$ in this area is less than $-\beta_{1} x_{1}$. The same arguments hold for $y_{2}$, so that $(0,0)$ is indeed one possible equilibrium.

But now assume that $y_{2}$ equals one. Since all $u_{1}$ in this area are greater than $-\beta_{1} x_{1}-$ $\gamma_{12}, y_{1}$ will equal one, too. The same reasoning can be applied to $y_{2}$ so that $(1,1)$ is also an equilibrium.

Therefore two equilibria, $(1,1)$ and $(0,0)$, are consistent with values out of this region. This nonexistence of a unique equilibrium implies that the sum of the probabilities for the distinct outcomes $(0,0),(1,0),(0,1)$ and $(1,1)$ is greater than one therefore making the definition of a random variable impossible.

Now consider the case where e.g. $\gamma_{12}$ is set equal to zero (see figure IV). The correspondence between $\left(u_{1}, u_{2}\right)$ and $\left(y_{1}, y_{2}\right)$ now becomes a function, since there are no more regions with multiple or no equilibria. The same holds true if $\gamma_{21}$ or both $\gamma_{12}$ and $\gamma_{21}$ are set to zero. The parameter restriction which ensures that the model (26) - (28) is coherent therefore can be stated as $\gamma_{12} \gamma_{21}=0$.

\footnotetext{
${ }^{20}$ See e.g. Butler and Picone (1999).

${ }^{21}$ The same arguments also hold for other signs of $\gamma_{12}$ and $\gamma_{21}$.
} 


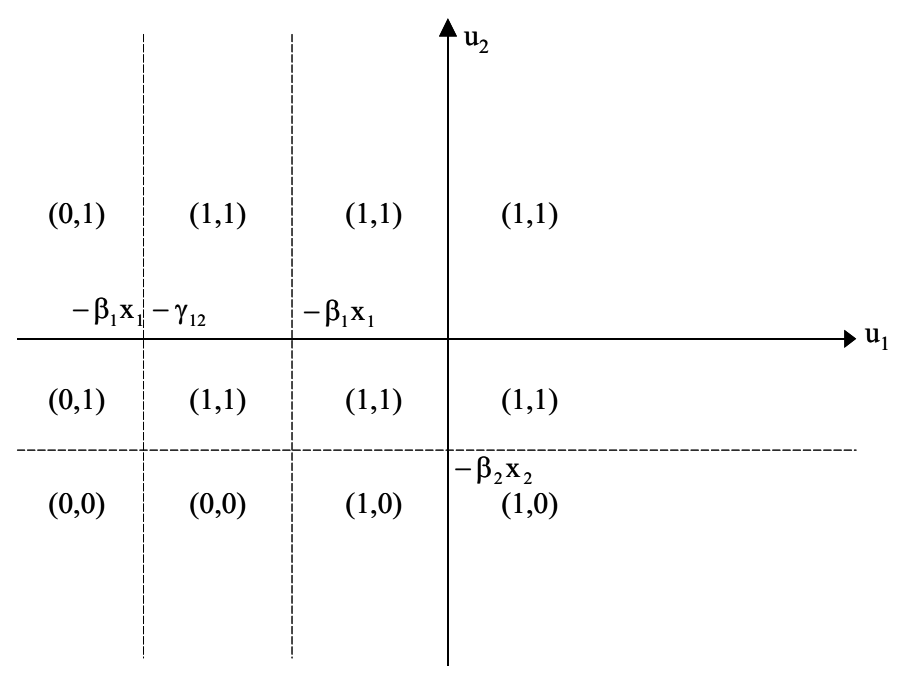

Figure IV: Simultaneous Probit Model with Unique Equilibria

A conclusion from the previous considerations is that a two equation type II Probit model in order to be coherent must feature a recursive structure between the endogenous variables. This restriction often rules out interesting interactions between the variables. In the following we will examine the impacts of this restrictive assumption for our empirical application.

But before, we will extend our findings to the general case. Consider the following $n$-simultaneous equation type II Probit model ${ }^{22}$

$$
\Gamma^{*} y^{*}+\Gamma y+B x=u
$$

where all $G$ variables in $y$ are assumed to be truncated and linked via a Probit threshold model with their latent counterpart in $y^{*}$. We further assume in (29) that only the observable variables appear as explanatory variables by setting $\Gamma^{*}=I$.

It can be shown that a necessary condition for the coherency of (29) is that all principle minors of $\Gamma$ are equal to zero. ${ }^{23}$ In our previously discussed example it holds that

$$
\Gamma=\left(\begin{array}{cc}
0 & -\gamma_{12} \\
-\gamma_{21} & 0
\end{array}\right)
$$

The principle minors of $\Gamma$ are

$$
\left|\Gamma_{11}\right|=0, \quad\left|\Gamma_{22}\right|=0 \quad \text { and } \quad|\Gamma|=-\gamma_{12} \gamma_{21} .
$$

The coherency condition therefore is that $\gamma_{12} \gamma_{21}$ must equal zero.

Now assume that only $G^{*} \leq G$ of the endogenous variables in $y$ are truncated. Partitioning the matrices accordingly, (29) can be written as

$$
\left(\begin{array}{ll}
y_{1}^{*} & y_{2}
\end{array}\right)=\left(\begin{array}{ll}
y_{1} & y_{2}
\end{array}\right)\left(\begin{array}{ll}
\Gamma_{11} & \Gamma_{12} \\
\Gamma_{21} & \Gamma_{22}
\end{array}\right)+X\left(\begin{array}{ll}
B_{1} & B_{2}
\end{array}\right)+\left(\begin{array}{ll}
u_{1} & u_{2}
\end{array}\right)
$$

where $y_{1}$ are the truncated and $y_{2}=y_{2}^{*}$ the observable variables.

\footnotetext{
${ }^{22}$ Again we skip the individual index for convenience.

${ }^{23}$ See Schmidt (1990) for a proof.
} 
(32) can be written as

$$
\begin{aligned}
& y_{1}^{*}=y_{1} \Gamma_{11}+y_{2} \Gamma_{21}+X B_{1}+u_{1} \\
& y_{2}=y_{1} \Gamma_{12}+y_{2} \Gamma_{22}+X B_{2}+u_{2} .
\end{aligned}
$$

(34) can be analogously written as

$$
y_{2}=y_{1} \Gamma_{12}\left(I-\Gamma_{22}\right)^{-1}+X B_{2}\left(I-\Gamma_{22}\right)^{-1}+u_{2}\left(I-\Gamma_{22}\right)^{-1} .
$$

Inserting (35) into (33) yields after rearranging

$$
\begin{aligned}
y_{1}^{*}= & y_{1}\left(\Gamma_{11}+\Gamma_{12}\left(I-\Gamma_{22}\right)^{-1} \Gamma_{21}\right)+X\left(B_{1}+B_{2}\left(I-\Gamma_{22}\right)^{-1} \Gamma_{21}\right) \\
& +\left(u_{1}+u_{2}\left(I-\Gamma_{22}\right)^{-1} \Gamma_{21}\right) .
\end{aligned}
$$

(36) is nothing else than the previously discussed simultaneous Probit type II model with all endogenous variables truncated. Applying the appropriate coherency condition yields that all principle minors of $\left(\Gamma_{11}+\Gamma_{12}\left(I-\Gamma_{22}\right)^{-1} \Gamma_{21}\right.$ must be zero.

Until now we have assumed that only the observable variables appear as explanatory variables. Consider now a model where both the latent and the observable variables appear as right hand side variables

$$
\Gamma^{*} y^{*}+\Gamma y+B x=u .
$$

Solving (37) for $y^{*}$ yields

$$
y^{*}=\Gamma^{*-1} \Gamma y-\Gamma^{*-1} B x+\Gamma^{*-1} u
$$

which is coherent if all principle minors of $\Gamma^{*-1} \Gamma$ are equal to zero. The next table summarizes the coherency conditions for the different models discussed previously.

TABLE I

Coherency Conditions for Simultaneous Probit Models

\begin{tabular}{cc}
\hline \hline Type II Model & Coherency Conditions \\
\hline Simultaneous Probit Model with All & All Principle Minors of \\
Endogenous Variables Truncated: & $\Gamma$ Must Equal Zero. \\
$Y^{*}=Y \Gamma+X B+\epsilon$. & \\
Simultaneous Probit Model with & All Principle Minors of \\
Some Endogenous Variables Truncated: & $I-\Gamma_{11}+\Gamma_{12}\left(I-\Gamma_{22}\right)^{-1} \Gamma_{21}$ \\
$\left(\begin{array}{ll}Y_{1}^{*} & Y_{2}\end{array}\right)=\left(\begin{array}{ll}Y_{1} & Y_{2}\end{array}\right)\left(\begin{array}{ll}\Gamma_{11} & \Gamma_{12} \\
\Gamma_{21} & \Gamma_{22}\end{array}\right)+X B+\epsilon$. & Must Equal Zero. \\
Simultaneous Probit Model with Both & All Principal Minors of \\
$Y$ and $Y^{*}$ as Explanatory Variables: & $\Gamma(I-\Delta)^{-1}$ Must Equal Zero. \\
$Y^{*}=Y \Gamma+X B+\epsilon$. & \\
\hline \hline
\end{tabular}

Let us now return to our empirical application as summarized in (10) - (14). $\Gamma^{*}$ and $\Gamma$ then become

$$
\Gamma^{*}=\left(\begin{array}{cccc}
1 & 0 & 0 & 0 \\
0 & 1 & 0 & 0 \\
0 & 0 & 1 & 0 \\
0 & 0 & 0 & 1
\end{array}\right) \quad \text { and } \quad \Gamma=\left(\begin{array}{cccc}
0 & 0 & \gamma_{13} & \gamma_{14} \\
0 & 0 & \gamma_{23} & \gamma_{24} \\
0 & 0 & 0 & \gamma_{34} \\
0 & 0 & \gamma_{43} & 0
\end{array}\right)
$$


Rearranging $\Gamma$ according to (32), we conclude that all principal minors of

$$
\left(\begin{array}{cc}
0 & \gamma_{43} \\
\gamma_{34} & 0
\end{array}\right)
$$

must be zero, i.e. either $\gamma_{34}=0$ or $\gamma_{43}=0$ leading to a recursive structure regarding the innovation decision and introduced organizational changes. In the following we will estimate two different type II models.

The first one (see figure $\mathrm{V}$ left) assumes that the innovation decision might have an impact on introduced organizational changes but not vice versa whereas the second model to be estimated assumes the converse (figure $\mathrm{V}$ right).
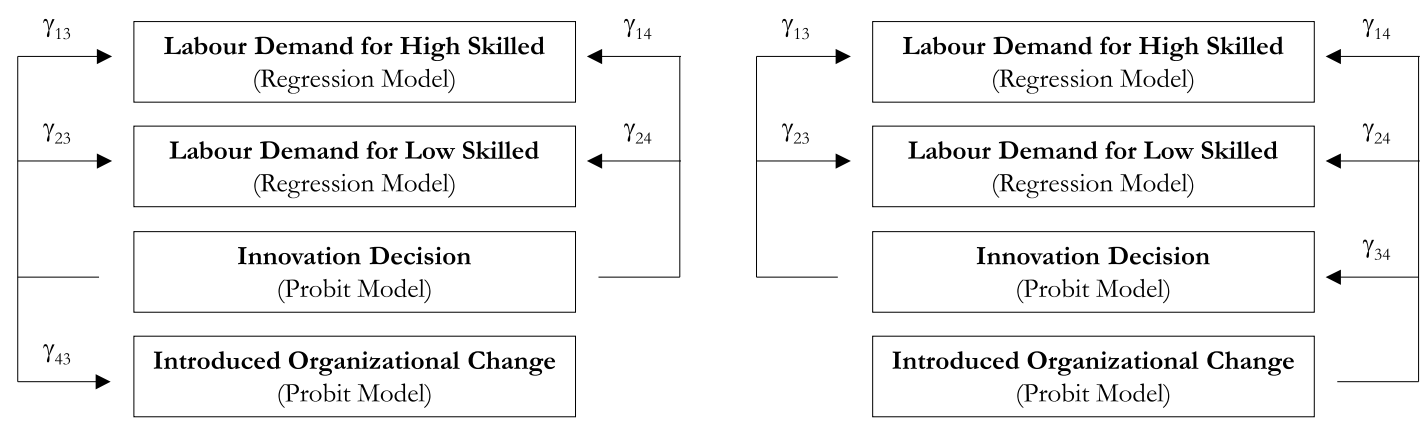

Figure V: Type II Dependency Structure And Econometric Models

\subsubsection{Estimation of Type II Models}

For the estimation of the parameters of type II models there are again two different approaches that can be followed. System estimation procedures are computationally more challenging since they require the evaluation of a $n$-fold integral in the case of a MSEM with $n$ Probit equations. This problem can be avoided by the use of single equation estimation procedures which are in fact instrumental variable estimators. We will describe this approach in the following.

One natural idea for estimating the structural form parameters of the model formulated in (10) - (13) with the parameter restriction $\gamma_{34} \gamma_{43}=0$, is to proceed in the following manner: For $\gamma_{43}=0$, the model can be rewritten $\mathrm{as}^{24}$

$$
\begin{aligned}
& S_{h i g h}=\gamma_{13} E(I N N O)+\gamma_{14} E(O R G A)+\beta_{h i g h}^{\prime} x_{h i g h} \\
& +\underbrace{\left(\gamma_{13}(I N N O-E(I N N O))+\gamma_{14}(O R G A-E(O R G A))+u_{h i g h}\right)}_{\equiv v_{\text {high }}} \\
& S_{\text {low }}=\gamma_{23} E(I N N O)+\gamma_{24} E(O R G A)+\beta_{\text {low }}^{\prime} x_{\text {low }} \\
& +\underbrace{\left(\gamma_{23}(I N N O-E(I N N O))+\gamma_{24}(O R G A-E(O R G A))+u_{\text {low }}\right)}_{\equiv v_{\text {low }}} \\
& I N N O^{*}=\gamma_{34} E(O R G A)+\beta_{\text {inno }}^{\prime} x_{i n n o}+\underbrace{\left(\gamma_{34}\left(O R G A-E(O R G A)+u_{\text {inno }}\right)\right)}_{\equiv v_{\text {inno }}}
\end{aligned}
$$

\footnotetext{
${ }^{24}$ See Wilde (1999).
} 


$$
O R G A^{*}=\beta_{\text {orga }}^{\prime} x_{\text {orga }}+u_{\text {orga }} .
$$

In a first step equation (44) can be estimated using standard ML-methods. The so obtained parameters are then used for estimating equation (43) by inserting the following expression for the expected value of $O R G A$

$$
E(O R G A)=P(O R G A=1)=P\left(u_{\text {orga }} \geq-\beta_{\text {orga }}^{\prime} x_{\text {orga }}\right)=\Phi\left(\beta_{\text {orga }}^{\prime} x_{\text {orga }}\right)
$$

and replacing $\beta_{\text {orga }}$ with the first step estimate $\hat{\beta}_{\text {orga }}$.

Finally, the employment share equations in (41) and (42) can be estimated using (45), inserting the following expression for the expected value of $I N N O$

$$
\begin{aligned}
E(I N N O)= & P(I N N O=1 \mid O R G A=1) P(O R G A=1) \\
& +P(I N N O=1 \mid O R G A=0) P(O R G A=0) \\
= & P\left(v_{\text {inno }} \geq-\gamma_{34}-\beta_{\text {inno }}^{\prime} x_{\text {inno }}\right) P\left(u_{\text {orga }} \geq-\beta_{\text {orga }}^{\prime} x_{\text {orga }}\right) \\
& +P\left(v_{\text {inno }} \geq-\beta_{\text {inno }}^{\prime} x_{\text {inno }}\right) P\left(u_{\text {orga }}<-\beta_{\text {orga }}^{\prime} x_{\text {orga }}\right) \\
= & \Phi\left(\gamma_{34}+\beta_{\text {inno }}^{\prime} x_{\text {inno }}\right) \Phi\left(\beta_{\text {orga }}^{\prime} x_{\text {orga }}\right) \\
& +\Phi\left(\beta_{\text {inno }}^{\prime} x_{\text {inno }}\right)\left(1-\Phi\left(\beta_{\text {orga }}^{\prime} x_{\text {orga }}\right)\right)
\end{aligned}
$$

and replacing $\beta_{\text {inno }}$ with $\hat{\beta}_{\text {inno }}$ obtained in the previous step.

One problem with this proceeding is, however, that the error terms in (41) - (43) are not distributed according to a normal distribution since $v_{\text {high }}, v_{\text {low }}$ and $v_{\text {inno }}$ are linear combinations of a continuous normal and a discrete binomial random variable. To account for this misspecification we will estimate the variances of the parameters using the variance estimator proposed by White (1982). The estimation results can be found in the appendix in the column labelled IV-White and will be discussed in section five.

\section{Dataset AND Descriptive Results}

In the following we will give a brief overview of the data set used in our empirical analysis, namely the IAB establishment panel and present some first descriptive results.

The IAB establishment panel is a yearly survey of the demand side situation of the labour market. ${ }^{25}$ The unit of interest is the establishment, i.e. the local unit where the activity of a company takes place. The basis for the IAB establishment panel is the employment statistics register of the Federal Employment Office ('Bundesanstalt für Arbeit'), where employers have to report information regarding their employees subject to a social compulsory security scheme. Starting from this register a stratified representative sample is drawn. The IAB panel started in 1993 with about 4,200 establishments from West-Germany. Since 1996 establishments from East-Germany are also included in the data set that in 1998 contained about 10,300 units. $^{26}$

The IAB panel is organized in a modular form. There are topics covered annually like changes in the level and structure of employment and questions about the establishment policy, e.g. information about the business volume and investment. Other topics are only covered irregularly, e.g. information about innovations and organizational changes. Additionally, there is also a special questionnaire about actual questions included into the panel every year.

\footnotetext{
${ }^{25}$ For a more thorough discussion see Kölling (2000) or Bellmann and Kölling (2000).

${ }^{26}$ It should be noted that the IAB establishment panel is not representative for all firms in Germany since the selection probability increases with the size of the establishment therefore leading to an overrepresentation of large establishments. See e.g. Bellmann (1997).
} 
Information about innovations are provided for the years 1993, 1994 and 1998 whereas organizational changes are covered in 1995, 1998 and 2000. Since the 1998 wave contains information about innovation decisions and organizational changes, we will focus our attention especially on this wave.

Regarding the innovation decision the following questions were posed:

- Has your establishment improved an already offered product or service during the last two years? (Improvement)

- Has your establishment included a new product or service in its range of products during the last two years that already existed in the market? (Incremental)

- Has your establishment included a new product or service in its range of products during the last two years that were new for the market? (Radical)

In 1995 and 1998 establishments were also asked if they have introduced one of the following organizational changes during the last two years:

- Reorganization of departments and functional areas (Reorganization),

- decentralization of responsibilities and decision-authority (Decentralization),

- introduction of group-workplaces with own responsibilities (Responsibility) or

- introduction of units with own costing and result calculation (Own Costing).

The questions about the innovation decisions and organizational changes are retrospective in nature so that we decided to also include information from the 1996 wave and thus to focus our attention on those establishments which participated in 1998 and 1996. The total number of theses establishments amounts to 6,970 with 3,564 coming from West- and 3,407 from East-Germany.

In the following we will present some first descriptive results for these establishments. Figure A.I in the appendix shows the distribution of the establishments with regard to the industrial affiliation, whereas figure A.II shows how they are divided into different size classes. The following table II shows the average number of employees in the different qualification groups.

TABLE II

DESCRIPTIVE RESULtS:

Mean and Standard Deviation for Different Skill Groups of Employees

\begin{tabular}{ccc}
\hline \hline Employees & Mean & Standard Deviation \\
\hline Low Skilled Blue Collar & 60.4 & 343.57 \\
High Skilled Blue Collar & 88.56 & 443.28 \\
Low Skilled White Collar & 19.59 & 136.05 \\
High Skilled White Collar & 173.31 & 569.64 \\
Apprentices and Working Owners & 16.51 & 51.12 \\
\hline Total Employment & 360.72 & 1167.24 \\
\hline \hline
\end{tabular}

Figure A.IV to A.VIII in the appendix show the percentage of establishments that introduced different forms of innovations with regard to size class, region and industrial affiliation. It can be concluded that especially large establishments in the primary industry, investments goods industry, finance and insurance are the innovative ones. Additionally West-German establishments compared to their eastern counterparts are more innovative. 
Estimating the Pearson correlation coefficient between the different forms of innovations reveals that there are positive and significant correlations between them, especially between an improvement of existing products and services and an incremental product innovation (see table A.XVI in the appendix). Due to these high positive correlations we decided to combine the different innovation forms to one single dummy variable, INNO, which equals one if at least one of the innovation forms is realized and zero otherwise.

In the following we will examine organizational changes introduced by the establishments. Figures A.IX to A.XIV in the appendix show the percentage of establishments that introduced different organizational changes with regard to size class, region and industrial affiliation. Again it is striking that especially large establishments in the electricity/mining segment, primary industry, investments goods industry and finance segment are those that introduced organizational changes. Additionally, West-German establishments are more likely to introduce organizational changes compared to their eastern counterparts.

Estimating the Pearson correlation coefficient between the different organizational changes reveals that there are positive and significant correlations between them as it was the case for the different forms of innovations (see table A.XVII in the appendix). Due to these high positive correlations we decided to combine the different organizational changes to one single dummy variable, $O R G A$, which equals one if at least one of the changes is realized and zero otherwise.

Having provided a first overview about the establishments which have introduced innovations and organizational changes, finally we will take a first look at the employment effects. To this aim we compare the employment shares for high and low skilled employees in 1998 for those establishments which have introduced innovations and organizational changes with establishments which have not.

More specifically we will distinguish the following establishments: Establishments which have introduced product innovations and organizational changes $(I N N O=$ $1, O R G A=1)$, establishments which introduced either innovations or organizational changes $(I N N O=1, O R G A=0$ and $I N N O=0, O R G A=1)$ and establishments which have introduced neither innovations nor organizational changes $(I N N O=0, O R G A=$ 0 ). Table A.XVIII in the appendix contains the percentages of the total 6,970 establishments falling in each category. The Pearson correlation coefficient between $I N N O$ and $O R G A$ equals 0.39 and is highly significant (significance level $<0.001$ ) indicating that innovations and organizational changes are indeed, as already stated above, closely related to each other.

Table III contains the means and standard deviations for the different employment shares. ${ }^{27}$ One striking feature is that establishments which introduced either innovations or organizational changes are the ones with the higher share of skilled employees in contrast to establishments which have introduced neither innovations nor organizational changes. This impression is confirmed by a look at the development of the shares for high and low skilled employees between 1998 and 1996 (see table III). Again establishments which introduced either innovations or organizational changes are the ones with a higher increase of high skilled employees and a higher decrease of low skilled employees.

These descriptive results give a first evidence for the hypothesis that there is a skill biased technological and organizational change in favour of high skilled employees. In the following we will test whether these first descriptive results are confirmed by the estimation results of the econometric models.

\footnotetext{
${ }^{27}$ Note that the shares do not sum to $100 \%$ since we have omitted other employment groups such as apprentices and working owners.
} 
TABLE III

DESCRIPTIVE RESULTS:

Shares and Development of Shares of High and Low

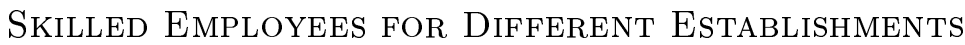

(Standard DeViations in BRACKets)

\begin{tabular}{ccccc}
\hline \hline \multirow{2}{*}{ Employment Group } & $\begin{array}{c}I N N O=0 \\
\text { ORGA }=0\end{array}$ & $\begin{array}{c}\text { INNO=1 } \\
\text { ORGA=0 }\end{array}$ & $\begin{array}{c}\text { INNO=0 } \\
\text { ORGA=1 }\end{array}$ & $\begin{array}{c}\text { INNO=1 } \\
\text { ORGA }=1\end{array}$ \\
\hline \multirow{2}{*}{ Share High Skilled } & $68 \%$ & $69 \%$ & $74 \%$ & $73 \%$ \\
& $(32.66)$ & $(29.21)$ & $(29.36)$ & $(24.99)$ \\
Growth High Skilled & $0.78 \%$ & $1.74 \%$ & $2.39 \%$ & $1.22 \%$ \\
& $(32.52)$ & $(26.64)$ & $(24.07)$ & $(19.73)$ \\
Share Low Skilled & $26 \%$ & $24 \%$ & $20 \%$ & $22 \%$ \\
& $(32.90)$ & $(29.17)$ & $(26.59)$ & $(24.97)$ \\
Growth Low Skilled & $-1.30 \%$ & $-2.09 \%$ & $-2.49 \%$ & $-1.90 \%$ \\
& $(31.75)$ & $(26.78)$ & $(23.23)$ & $(19.15)$ \\
\hline \hline
\end{tabular}

\section{Estimation Results}

In this paper we were mainly interested in the employment effects of innovations and organizational changes. To this aim several econometric models were estimated using different estimation methods, ranging from separate estimation of the employment share, innovation and organizational change equation to models and methods which take the endogeneity of innovations and organizational changes into account.

Thereby we employed two different types of models, namely type I models which assume that it is the propensity to innovate or to introduce organizational changes which might have an impact on the demand for heterogenous labour, and type II models which on the other hand assume that it is the actual decision that has an effect. The detailed estimation results can be found in the appendix. In the following we will summarize the main findings and derive some stylized facts. We start with the relations between the endogenous variables, namely share of high and low skilled employees, innovations and organizational changes (see figure VI).

By comparing the estimation results for the different models, the following stylized facts can be derived: Both type I and type II models support the hypothesis about a skill biased technological change in favour of high skilled employees. For the type I model, estimation based on the procedure proposed by Amemiya yields no significant results whereas the estimation based on Nelson-Olson confirms the OLS estimation results, namely that innovations have a positive impact on high skilled and a negative on low skilled employees. The same holds for both recursive type II models that were estimated, the first which assumes that innovations have an impact on organizational changes $(I N N O \rightarrow O R G A)$ and the second which assumes the opposite, i.e. ORGA $\rightarrow I N N O$.

At this point one natural arising question is the following: Do only implemented innovations and organizational changes have an impact on the labour demand or even the propensity to do so, i.e. are type I or type II models more appropriate? To this aim we will conduct a simple test proposed by Blundell and Smith (1993) and Davidson and MacKinnon (1981) that will allow us to discriminate between them.

At first we will test whether the type I formulation of our model is appropriate, i.e. 


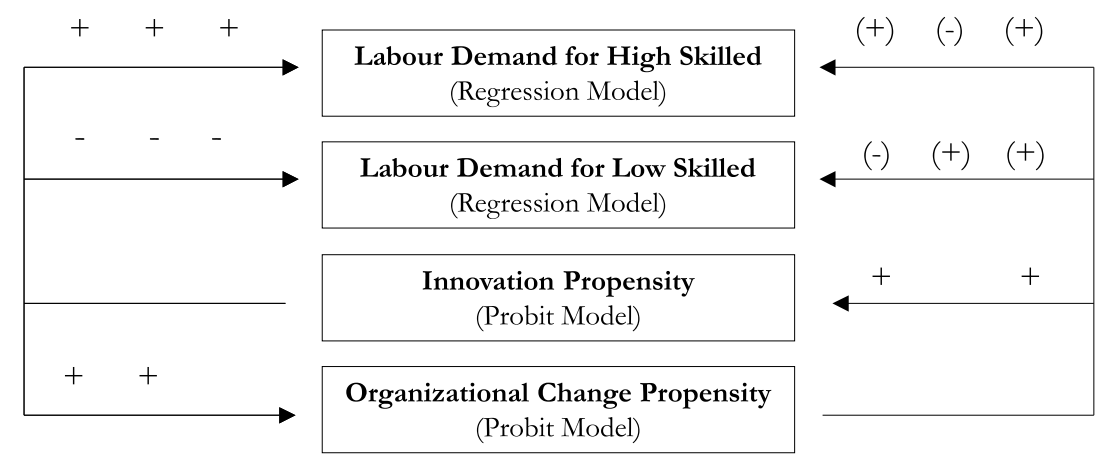

\begin{tabular}{|c|c|c|}
\hline Type I Model & $\begin{array}{l}\text { Type II Model } \\
\text { (Inno } \rightarrow \text { Orga })\end{array}$ & $\begin{array}{l}\text { Type II Model } \\
(\text { Orga } \rightarrow \text { Inno) }\end{array}$ \\
\hline
\end{tabular}

\section{Figure Vi: Estimation Results for Different Models (Only the Signs are Reported, Insignificant Parameters in Brackets)}

our null hypothesis is

$$
H_{0}: \quad \text { Type I model is the true model }
$$

and the two alternative hypotheses are

$$
\begin{array}{ll}
H_{1}: & \text { Type II model }(I N N O \rightarrow O R G A) \text { is the true model } \\
H_{2}: & \text { Type II model }(O R G A \rightarrow I N N O) \text { is the true model. }
\end{array}
$$

If the type I formulation is the true model, then for the share equation for high and low skilled employees, $S_{\text {high }}$ and $S_{\text {low }}$, explicit reduced form equations exist

$$
\begin{aligned}
& S_{\text {high }}=\pi_{\text {high }}^{\prime} x+v_{\text {high }} \\
& S_{\text {low }}=\pi_{\text {low }}^{\prime} x+v_{\text {low }} .
\end{aligned}
$$

If, however, the type II formulation is the correct one, then only a semireduced form is available which also contains the endogenous dummy variables

$$
\begin{aligned}
& S_{\text {high }}=\pi_{\text {high }}^{\prime} x+\gamma_{13} I N N O+\gamma_{14} \text { ORGA }+v_{\text {high }} \\
& S_{\text {low }}=\pi_{\text {low }}^{\prime} x+\gamma_{23} I N N O+\gamma_{24} O R G A+v_{\text {low }} .
\end{aligned}
$$

One obvious way to test $H_{0}$ therefore consists in estimating (51) by replacing $I N N O$ and $O R G A$ by the appropriate estimated predictions under the type II formulation and test if $\gamma_{13}=\gamma_{14}=0$ and $\gamma_{23}=\gamma_{24}=0$ respectively. ${ }^{28}$

The results can be found in the following table IV. They indicate that $H_{0}$ can not be rejected, i.e. the type I formulation is appropriate for the share equation of high and low skilled employees. We conclude that it is not only the actual decision to innovate and to introduce organizational changes that affects the labour demand but also the propensity to do so.

\footnotetext{
${ }^{28}$ For the type II model e.g. with $\gamma_{43}=0$, i.e. the INNO $\rightarrow$ ORGA model, $E(O R G A)=\Phi\left(\hat{\beta}_{\text {orga }}^{\prime} x_{\text {orga }}\right)$ and $E(I N N O)=\Phi\left(\hat{\gamma}_{34}+\hat{\beta}_{\text {inno }}^{\prime} x_{\text {inno }}\right) \Phi\left(\hat{\beta}_{\text {orga }}^{\prime} x_{\text {orga }}\right)+\Phi\left(\hat{\beta}_{\text {inno }}^{\prime} x_{\text {inno }}\right)\left(1-\Phi\left(\hat{\beta}_{\text {orga }}^{\prime} x_{\text {orga }}\right)\right.$.
} 
TABLE IV

Model Specification Test:

$H_{0}$ : Type I model is the true model for High and Low Skilled

\begin{tabular}{ccc}
\hline \hline$H_{\text {alternative }}$ & F-Value & p-Value \\
\hline Type II $(I N N O \rightarrow O R G A)$ is the True Model for High Skilled & 0.56 & 0.57 \\
Type II $(I N N O \rightarrow O R G A)$ is the True Model for Low Skilled & 0.96 & 0.38 \\
Type II $(O R G A \rightarrow I N N O)$ is the True Model for High Skilled & 1.64 & 0.19 \\
Type II $(O R G A \rightarrow I N N O)$ is the True Model for Low Skilled & 0.70 & 0.50 \\
\hline \hline
\end{tabular}

Next we will test if our data are also consistent with the type II formulation. The type II formulation can be tested by estimating ${ }^{29}$

$$
\begin{aligned}
& S_{\text {high }}=\gamma_{13} I N N O+\gamma_{14} O R G A+\beta_{\text {high }}^{\prime} x_{\text {high }}+\delta_{\text {high }} \hat{S}_{\text {high }}+u_{\text {high }} \\
& S_{\text {low }}=\gamma_{23} I N N O+\gamma_{24} O R G A+\beta_{\text {low }}^{\prime} x_{\text {low }}+\delta_{\text {low }} \hat{S}_{\text {low }}+u_{\text {low }}
\end{aligned}
$$

and testing if $\delta_{\text {high }}=0$ and $\delta_{\text {low }}=0$ respectively. Thereby $\hat{S}_{\text {high }}$ and $\hat{S}_{\text {low }}$ are the estimated predictions under the type I explicit linear reduced form for $S_{h i g h}$ and $S_{l o w}$. The following table $\mathrm{V}$ contains the t-values and significance levels for $\delta_{\text {high }}$ and $\delta_{\text {low }}$.

TABLE V

Model Specification Test:

$H_{0}$ : Type II Model is the true MOdel For High AND Low Skilled

\begin{tabular}{ccc}
\hline \hline$H_{\text {alternative }}$ & $\mathrm{t}$-Value & $\mathrm{p}$-Value \\
\hline Type I is the True Model for High Skilled & 34.67 & $<0.0001$ \\
Type I is the True Model for Low Skilled & 32.66 & $<0.0001$ \\
\hline \hline
\end{tabular}

Since the null hypothesis is rejected on a high significance level we conclude that type II models are not appropriate in our context compared with type I models. It seems therefore that the censoring of the INNO and $O R G A$ variables acts as an observation constraint for the econometrician but not for the establishment. Establishments seem to have the choice between a whole scope of innovation decisions which affect the labour demand and not only between the ones observed in the dataset.

We continue with other factors that have a significant impact on the labour demand. These are first of all investments in information and communication technology. Again the effect is diametral regarding different skill groups of employees, i.e. positive for high and negative for low skilled. The state of the technology of an establishment works in the same direction: The newer the technology, the more likely high skilled employees will be employed.

With regard to organizational changes no significant effects on the labour demand can be observed, independent of the econometric model. We thus found no empirical support for our initially formulated hypothesis that organizational changes might also have a skill biased impact on the labour demand.

Another striking feature of our estimation results concerns the relation between innovations and organizational changes. Any estimated model points out that introduced innovations and organizational changes are closely related to each other.

${ }^{29}$ See Blundell and Smith (1993). 
The major factors driving innovations are the age of the technology used (a modern equipment increases the probability to innovate), the existence of a research \& development and a market research department, the competition pressure (with an increasing competition the probability to innovate increases) and the size of the establishment (larger establishments are more likely to innovate than smaller ones). Interestingly the portion of high skilled employees has no effect on the innovation activities.

Regarding the decision of establishments to introduce organizational changes the following factors can be identified: Investments in information and communication technology increase the probability to introduce organizational changes thereby supporting our initially formulated hypothesis about the relation between technological and organizational change. Other driving factors are the business development (an insufficient development increases the probability to introduce organizational changes), the existence of a workers and staff council and the size of the establishment which both increase the probability to introduce organizational changes. Again the portion of skilled employees has no significant effect.

\section{Conclusions and OUtLoOK}

The purpose of this paper was to answer the following questions: What is the effect of technological change on the labour demand, especially for different skill groups of employees? Does the numerous recently introduced organizational changes also have an effect on the labour demand? Which effect prevails: Innovations or organizational changes? If technological progress and organizational changes are indeed skill biased as often stated, what is the net effect on the total labour demand?

Another interesting point is the following: Do only implemented innovations and organizational changes have an impact on the labour demand or even the propensity to do so, i.e. are type I or type II models more appropriate?

Finally, we wanted to know if certain organizational environments are more likely to generate innovations or if innovations entail organizational changes?

Our results indicate that product innovations operate in an asymmetrical way, increasing the labour demand for high and reducing it for low skilled employees. For organizational changes we did not find a similar effect. By comparing the absolute numbers of the innovation effect on the labour demand for high and low skilled employees, it seems that the total labour demand effect is almost zero, but noticeable larger for type II models than for the type I model. This means that implemented innovations affect the labour demand more severely than only the propensity to innovate.

By conducting several specification tests in order to discriminate between type I and type II models, we arrived at the insight that models which assume that the propensity to innovate and to introduce organizational changes have an impact on the labour demand are more appropriate than models which assume that it is the actual decision to do so. It thus seems that the censoring of the variables acts as an observational constraint for the econometrician but not for the set of choices of the individual establishment.

One additional finding is the close relation between innovations and organizational changes. Every estimated model pointed out that innovations are always associated with organizational changes and vice versa.

Our empirical findings, however, have a number of drawbacks which must be taken into account. The first point concerns the crude measure for different skill groups. Our dataset does not contain any information about the education or the actual activities of the employees. Furthermore due to data limitations we were forced to approximate the wages for different skill groups using industry dummies. 
Since we had no information about introduced process innovations, our econometric model solely focused on product innovations. We were therefore not able to test if product as opposed to process innovations have a different effect on the labour demand, an effect that is likely to be expected as theoretical considerations suggest. Unobserved heterogeneity certainly plays a major role in the innovation process of establishments, which could only be taken into account by employing a panel dataset but not by using only a cross sectional dataset as in our case.

We hope to accommodate these requirements and to mitigate the shortcomings of our findings in future work by employing a linked employer-employee dataset for more than one year. 


\section{APPENDIX}

TABLE A.I

VARIABles Used FOR THE EMPLOYMENT ShaRES IN $1998^{a}$

\begin{tabular}{cl}
\hline \hline Variable & \multicolumn{1}{c}{ Label } \\
\hline$I N V_{97} / Y_{97}$ & Logarithm of Total Investments in 1997 per Business Volume (in DEM) \\
$D E V_{97}$ & Business Development in $1997(1=$ Very good, $\ldots, 5=$ Insufficient) \\
$I C T_{97}$ & Investment in Information and Communication Technology in 1997 \\
& (Yes/No) \\
$C O M P$ & Competition Pressure $(1=$ No Pressure, $\ldots, 4=$ High Pressure) \\
$S T A T E_{98}$ & State of the Technology in $1998(1=\mathrm{Up}$-to-Date, $\ldots, 5=$ Out-of-Date) \\
$I N N O$ & Product Improvement, Incremental or Radical Innovation (Yes/No) ${ }^{b}$ \\
$O R G A$ & Introduced Organizational Changes (Yes/No $)^{c}$ \\
& 16 Industry Dummies with Reference Class Agriculture \\
& 16 Regional Dummies with Reference Class Eastern Berlin \\
\hline \hline
\end{tabular}

a The Share of High Skilled Employees thereby consists of Skilled Workers and White Collar Workers for Qualified Tasks, whereas Low Skilled Employees are made up of Un- and Semiskilled Blue Collar Workers and White Collar Workers and Officials for Simple Tasks.

${ }^{b}$ Consists of Improvement of Existing Products and Services, Introduction of New Products and Services for the Establishment and New Products and Services for the Market during 1996 and 1997.

$c$ Consists of Reorganization of Departments and Functional Areas, Decentralization of Responsibilities and Decision-Authority, Introduction of Group-Workplaces with Own Responsibilities and Introduction of Units with Own Costing and Result Calculation during 1996 and 1997. 
TABLE A.II

VARIABLES USED FOR THE INNOVATION DECISION ${ }^{a}$

\begin{tabular}{|c|c|}
\hline Variable & Label \\
\hline$H I G H_{96}$ & Share of High Qualified White and Blue Collar Employees in 1996 \\
\hline$R \& D$ & R\&D Department (Yes/No) \\
\hline$M R$ & Market Research Department (Yes/No) \\
\hline$O R G A$ & Introduced Organizational Changes (Yes/No) ${ }^{b}$ \\
\hline$P R O F$ & Profit Participation Plans for Employees (Yes/No) \\
\hline COOP & Engagement in R\&D Cooperation with other Institutions \\
\hline$I N V_{97}$ & Total Investments in 1997 (in DEM) \\
\hline$I C T_{95}$ & $\begin{array}{l}\text { Investment in Information and Communication Technology in } 1995 \\
\text { (Yes/No) }\end{array}$ \\
\hline$S T A T E_{96}$ & State of the Technology in 1996 ( $1=$ Up-to-Date $, \ldots, 5=$ Out-of-Date $)$ \\
\hline$D E V_{97}$ & Business Development in 1997 ( $1=$ Very good, $\ldots, 5=$ Insufficient $)$ \\
\hline$C O M P$ & Competition Pressure $(1=$ No Pressure $, \ldots, 4=$ High Pressure $)$ \\
\hline$O N E M A N$ & One Man Business ${ }^{c}$ \\
\hline$P A R T$ & Establishment Organized as a Business Partnership ${ }^{c}$ \\
\hline$L I M T D$ & Private Limited Company ${ }^{c}$ \\
\hline$C A P T$ & Capital Company $^{c}$ \\
\hline$P U B L$ & Public Corporation $^{c}$ \\
\hline$S I Z E_{50}$ & Establishment with Less than 50 Employees \\
\hline \multirow[t]{3}{*}{$S I Z E_{500}$} & Establishment with Less than 500 Employees \\
\hline & 16 Industry Dummies with Reference Class Agriculture \\
\hline & 16 Regional Dummies with Reference Class Eastern Berlin \\
\hline
\end{tabular}

${ }^{a}$ Consists of Improvement of Existing Products and Services, Introduction of New Products and Services for the Establishment and New Products and Services for the Market during 1996 and 1997.

${ }^{b}$ Consists of Reorganization of Departments and Functional Areas, Decentralization of Responsibilities and Decision-Authority, Introduction of Group-Workplaces with Own Responsibilities and Introduction of Units with Own Costing and Result Calculation during 1996 and 1997.

${ }^{c}$ Reference Class Consists of Miscellaneous Other Legal Forms, e.g. Cooperatives and Incorporated Societies. 
TABLE A.III

Variables Used for Introduced Organizational Changes $^{a}$

\begin{tabular}{|c|c|}
\hline Variable & Label \\
\hline$H I G H_{96}$ & Share of High Qualified White and Blue Collar Employees in 1996 \\
\hline$C O M P$ & Competition Pressure $(1=$ No Pressure $, \ldots, 4=$ High Pressure $)$ \\
\hline$D E V_{96}$ & Business Development in 1996 ( $1=$ Very good, $\ldots, 5=$ Insufficient $)$ \\
\hline$D E V_{97}$ & Business Development in 1997 ( $1=$ Very good, $\ldots, 5=$ Insufficient $)$ \\
\hline$I N N O$ & Product Improvement, Incremental or Radical Innovation (Yes/No) ${ }^{b}$ \\
\hline$I N V_{97}$ & Total Investments in 1997 (in DEM) \\
\hline$I C T_{95}$ & $\begin{array}{l}\text { Investment in Information and Communication Technology in } 1995 \\
\text { (Yes/No) }\end{array}$ \\
\hline$I C T_{97}$ & $\begin{array}{l}\text { Investment in Information and Communication Technology in } 1997 \\
\text { (Yes/No) }\end{array}$ \\
\hline$S T A T E_{96}$ & State of the Technology in 1996 ( $1=$ Up-to-Date $, \ldots, 5=$ Out-of-Date $)$ \\
\hline$U N I O N$ & Workers/Staff Council (Yes/No) \\
\hline$O N E M A N$ & One Man Business ${ }^{c}$ \\
\hline$P A R T$ & Establishment Organized as a Business Partnership ${ }^{c}$ \\
\hline$L I M T D$ & Private Limited Company ${ }^{c}$ \\
\hline$C A P T$ & Capital Company $^{c}$ \\
\hline$P U B L$ & Public Corporation $^{c}$ \\
\hline$S I Z E_{50}$ & Establishment with Less than 50 Employees \\
\hline \multirow[t]{3}{*}{$S I Z E_{500}$} & Establishment with Less than 500 Employees \\
\hline & 16 Industry Dummies with Reference Class Agriculture \\
\hline & 16 Country Dummies with Reference Class Eastern Berlin \\
\hline
\end{tabular}

${ }^{a}$ Consists of Reorganization of Departments and Functional Areas, Decentralization of Responsibilities and Decision-Authority, Introduction of Group-Workplaces with Own Responsibilities and Introduction of Units with Own Costing and Result Calculation during 1996 and 1997.

${ }^{b}$ Consists of Improvementb of Existing Products and Services, Introduction of New Products and Services for the Establishment and New Products and Services for the Market during 1996 and 1997.

${ }^{c}$ Reference Class Consists of Miscellaneous Other Legal Forms, e.g. Cooperatives and Incorporated Societies. 
TABLE A.IV

Estimation Results Type I Model:

Share Equation for High Skilled Employees

\begin{tabular}{ccccccc}
\hline \hline & \multicolumn{2}{c}{ OLS } & \multicolumn{2}{c}{ Amemiya } & \multicolumn{2}{c}{ Nelson-Olson } \\
Variable & Parameter & t-Value & Parameter & t-Value & Parameter & t-Value \\
\hline Intercept & 75.2796 & 18.01 & 35.6447 & 2.60 & 83.3970 & 18.95 \\
$I N V_{97} / Y_{97}$ & 0.0023 & 0.01 & 0.2902 & 0.03 & -0.4913 & -1.37 \\
$D E V_{97}$ & 0.8410 & 1.87 & 0.9076 & 0.10 & 0.5990 & 1.29 \\
$I C T_{97}$ & 4.4372 & 4.12 & 1.9770 & 0.20 & 2.1220 & 1.72 \\
$C O M P$ & -0.0024 & -0.00 & 0.5815 & 0.06 & -0.6359 & -0.89 \\
STATE $E_{98}$ & -1.2776 & -2.02 & -1.7081 & -0.19 & -0.8970 & -1.34 \\
\hline INNO & 3.1828 & 3.03 & -4.5698 & -0.49 & 3.4531 & 2.18 \\
ORGA & 2.2563 & 2.19 & 0.9922 & 0.29 & 1.5477 & 1.13 \\
\hline \multicolumn{7}{c}{ F-Value } \\
Industry & 19.08 & F-Value & F-Value \\
Region & 18.38 & 2.40 & 17.30 \\
\hline$R_{\text {adj }}^{2}$ & 0.1677 & 3.27 & 19.62 \\
\hline \hline
\end{tabular}

TABLE A.V

Estimation Results Type I Model:

Share Equation for Low Skilled Employees

\begin{tabular}{|c|c|c|c|c|c|c|}
\hline \multirow[b]{2}{*}{ Variable } & \multicolumn{2}{|c|}{ OLS } & \multicolumn{2}{|c|}{ Amemiya } & \multicolumn{2}{|c|}{ Nelson-Olson } \\
\hline & Parameter & t-Value & Parameter & t-Value & Parameter & t-Value \\
\hline Intercept & 17.3708 & 4.16 & 56.8459 & 5.27 & 10.3330 & 2.33 \\
\hline$I N V_{97} / Y_{97}$ & -0.1142 & -0.34 & -0.4634 & -0.06 & 0.2550 & 0.71 \\
\hline$D E V$ & -0.7244 & -1.61 & -1.0794 & -0.15 & -0.6593 & -1.41 \\
\hline$I C T_{97}$ & -3.3870 & -3.15 & -1.3579 & -0.18 & -2.0079 & -1.61 \\
\hline$C O M P$ & 0.0514 & 0.08 & -0.5794 & -0.08 & 0.5239 & 0.73 \\
\hline$S T A T E_{98}$ & 1.6038 & 2.54 & 2.1076 & 0.29 & 1.4275 & 2.12 \\
\hline$I N N O$ & -2.8812 & -2.75 & 5.3809 & 0.73 & -2.3635 & -1.48 \\
\hline \multirow[t]{2}{*}{$O R G A$} & -2.2677 & -2.21 & -1.8820 & -0.70 & -1.0399 & -0.76 \\
\hline & \multicolumn{2}{|c|}{ F-Value } & \multicolumn{2}{|c|}{ F-Value } & \multicolumn{2}{|c|}{ F-Value } \\
\hline Industry & \multicolumn{2}{|c|}{21.74} & \multicolumn{2}{|c|}{4.63} & \multicolumn{2}{|c|}{19.71} \\
\hline Region & \multicolumn{2}{|c|}{21.90} & \multicolumn{2}{|c|}{4.53} & \multicolumn{2}{|c|}{22.24} \\
\hline$R_{a d j}^{2}$ & \multicolumn{2}{|c|}{0.1893} & \multicolumn{2}{|c|}{-} & \multicolumn{2}{|c|}{0.1949} \\
\hline
\end{tabular}


TABLE A.VI

Estimation Results Type I Model: Innovation Decision

\begin{tabular}{|c|c|c|c|c|c|c|}
\hline \multirow[b]{2}{*}{ Variable } & \multicolumn{2}{|c|}{ ML } & \multicolumn{2}{|c|}{ Amemiya } & \multicolumn{2}{|c|}{ Nelson-Olson } \\
\hline & Parameter & t-Value & Parameter & t-Value & Parameter & t-Value \\
\hline Intercept & -1.2680 & -5.06 & -0.3896 & -29.9237 & -0.6247 & -2.03 \\
\hline$H I G H_{96}$ & 0.0015 & 1.92 & 0.0003 & 0.1100 & 0.0003 & 0.25 \\
\hline$R \& D$ & 0.6502 & 2.98 & 0.8459 & 65.4328 & 0.8298 & 3.08 \\
\hline$M R$ & 0.3591 & 7.60 & 0.1739 & 34.3940 & 0.1756 & 2.12 \\
\hline PROF & 0.1891 & 2.60 & 0.0335 & 4.7506 & 0.0269 & 0.23 \\
\hline COOP & 0.3069 & 1.35 & -0.0686 & -3.4896 & -0.0374 & -0.13 \\
\hline$I N V_{97}$ & $1.19 \mathrm{E}-9$ & 1.09 & $-4.50 \mathrm{E}-010$ & $-1.58 \mathrm{E}-007$ & $1.13 \mathrm{E}-10$ & 0.09 \\
\hline$I C T_{95}$ & 0.2532 & 5.43 & 0.0374 & 9.6453 & 0.0492 & 0.66 \\
\hline$S T A T E_{96}$ & -0.1036 & -3.80 & -0.0772 & -26.9107 & -0.1075 & -3.19 \\
\hline$D E V_{97}$ & -0.0192 & -0.91 & -0.0120 & -4.1653 & -0.0261 & -0.94 \\
\hline$C O M P$ & 0.1262 & 4.23 & 0.0638 & 22.1078 & 0.0557 & 1.42 \\
\hline$S I Z E_{50}$ & -0.2418 & -2.42 & -0.0373 & -4.2024 & 0.0007 & 0.00 \\
\hline$S I Z E_{500}$ & -0.3097 & -3.29 & -0.1767 & -32.7806 & -0.1733 & -1.38 \\
\hline$O N E M A N$ & 0.0433 & 0.36 & 0.1734 & 49.5953 & 0.1823 & 1.18 \\
\hline PART & 0.1360 & 1.04 & 0.2256 & 73.8131 & 0.2233 & 1.40 \\
\hline$L I M T D$ & 0.2362 & 2.07 & 0.2919 & 97.4241 & 0.2869 & 2.05 \\
\hline$C A P T$ & 0.1659 & 1.17 & 0.2946 & 75.0272 & 0.2520 & 1.42 \\
\hline$P U B L$ & 0.0782 & 0.49 & 0.0999 & 22.3531 & 0.0748 & 0.34 \\
\hline \multirow[t]{2}{*}{$O R G A$} & 0.5967 & 12.17 & 0.4748 & 38.2437 & 0.4719 & 3.67 \\
\hline & \multicolumn{2}{|c|}{ LR-Value } & \multicolumn{2}{|c|}{ F-Value } & \multicolumn{2}{|c|}{ LR-Value } \\
\hline Industry & \multicolumn{2}{|c|}{137.2174} & \multicolumn{2}{|c|}{91.76} & \multicolumn{2}{|c|}{96.9473} \\
\hline Region & \multicolumn{2}{|c|}{24.7570} & \multicolumn{2}{|c|}{3.73} & \multicolumn{2}{|c|}{11.6201} \\
\hline LR-Test & \multicolumn{2}{|c|}{8121.8093} & \multicolumn{2}{|c|}{-} & \multicolumn{2}{|c|}{5273.5230} \\
\hline
\end{tabular}


TABLE A.VII

Estimation Results Type I Model: Organizational Changes

\begin{tabular}{ccccccc}
\hline \hline & \multicolumn{2}{c}{ ML } & \multicolumn{2}{c}{ Amemiya } & \multicolumn{2}{c}{ Nelson-Olson } \\
Variable & Parameter & t-Value & Parameter & t-Value & Parameter & t-Value \\
\hline Intercept & -0.5805 & -2.25 & -0.2500 & -0.3285 & -0.1635 & -0.55 \\
HIGH $H_{96}$ & 0.0016 & 1.91 & 0.0004 & 0.0011 & 0.0007 & 0.72 \\
COMP & 0.1019 & 3.10 & -0.0179 & -0.0468 & 0.0278 & 0.71 \\
DEV $V_{96}$ & 0.0412 & 1.70 & 0.0460 & 0.1218 & 0.0520 & 1.84 \\
DEV $V_{97}$ & 0.0269 & 1.13 & 0.0423 & 0.1121 & 0.0441 & 1.59 \\
IN $V_{97}$ & $1.83 \mathrm{E}-9$ & 1.27 & $1.57 \mathrm{E}-009$ & $4.17 \mathrm{E}-009$ & $1.57 \mathrm{E}-9$ & 1.08 \\
ICT $T_{95}$ & 0.2424 & 4.97 & 0.1482 & 0.3755 & 0.1862 & 3.14 \\
ICT $T_{97}$ & 0.4402 & 8.77 & 0.2301 & 0.5632 & 0.3030 & 4.78 \\
UNION & 0.2404 & 3.76 & 0.1839 & 0.4849 & 0.2101 & 2.83 \\
SIZE $E_{50}$ & -0.8874 & -8.16 & -0.4021 & -0.8840 & -0.4558 & -3.61 \\
SIZE $E_{500}$ & -0.5118 & -5.22 & -0.1394 & -0.2997 & -0.1962 & -1.78 \\
ONEMAN & -0.4567 & -3.50 & -0.2803 & -0.7377 & -0.2682 & -1.80 \\
PART & -0.3350 & -2.41 & -0.2603 & -0.6624 & -0.2457 & -1.56 \\
LIMTD & -0.0822 & -0.67 & -0.1659 & -0.3728 & -0.0927 & -0.67 \\
CAPT & 0.23699 & 1.57 & -0.0528 & -0.1088 & 0.1020 & 0.59 \\
PUBL & 0.3815 & 1.79 & 0.1443 & 0.3438 & 0.2420 & 1.06 \\
\hline IN NO & 0.6360 & 13.25 & 0.7996 & 1.3982 & 0.5768 & 9.24 \\
\hline LR-Value & 12.1841 & F-Value & LR-Value \\
Industry & 23.7654 & 0.13 & 29.0652 \\
Region & 9703.0617 & 0.03 & 18.6007 \\
\hline LR-Test & \multicolumn{7}{c}{-} & & 6314.8505 \\
\hline \hline
\end{tabular}


TABLE A.VIII

Estimation Results TyPe II Model $(I N N O \rightarrow O R G A):$

Share Equation for High Skilled Employees

\begin{tabular}{ccccc}
\hline \hline & \multicolumn{2}{c}{ OLS } & \multicolumn{2}{c}{ IV-White } \\
Variable & Parameter & t-Value & Parameter & t-Value \\
\hline Intercept & 75.2796 & 18.01 & 75.7018 & 17.41 \\
$I N V_{97} / Y_{97}$ & 0.0023 & 0.01 & -0.2781 & -0.77 \\
$D E V_{97}$ & 0.8410 & 1.87 & 0.7518 & 1.62 \\
$I C T_{97}$ & 4.4372 & 4.12 & 2.9235 & 2.28 \\
$C O M P$ & -0.0024 & -0.00 & -1.1326 & -1.40 \\
STATE $E_{98}$ & -1.2776 & -2.02 & -0.8715 & -1.34 \\
\hline INNO & 3.1823 & 3.03 & 17.7980 & 3.36 \\
ORGA & 2.2563 & 2.19 & 1.2661 & 0.22 \\
\hline \multicolumn{5}{c}{ F-Value } \\
Industry & 19.08 & F-Value \\
Region & 18.38 & 18.44 \\
\hline$R_{\text {adj }}^{2}$ & 0.1677 & 20.06 \\
\hline \hline
\end{tabular}

TABLE A.IX

Estimation Results Type II Model $(I N N O \rightarrow O R G A)$ :

Share Equation for Low Skilled Employees

\begin{tabular}{ccccc}
\hline \hline & \multicolumn{2}{c}{ OLS } & \multicolumn{2}{c}{ IV-White } \\
Variable & Parameter & t-Value & Parameter & t-Value \\
\hline Intercept & 17.3708 & 4.16 & 15.2136 & 3.48 \\
IN $V_{97} / Y_{97}$ & -0.1142 & -0.34 & 0.1556 & 0.43 \\
$D E V$ & -0.7244 & -1.61 & -0.8512 & -1.85 \\
IC $T_{97}$ & -3.3870 & -3.15 & -3.0346 & -2.35 \\
COMP & 0.0514 & 0.08 & 0.9132 & 1.10 \\
ST ATE $E_{98}$ & 1.6038 & 2.54 & 1.3582 & 2.07 \\
\hline INNO & -2.8812 & -2.75 & -18.7135 & -3.46 \\
ORGA & -2.2677 & -2.21 & 5.0413 & 0.88 \\
\hline \multicolumn{5}{c}{ F-Value } \\
Industry & 21.74 & F-Value \\
Region & 21.90 & 21.71 \\
\hline$R_{\text {adj }}^{2}$ & 0.1893 & 23.06 \\
\hline \hline
\end{tabular}


TABLE A.X

Estimation Results Type II Model $(I N N O \rightarrow O R G A)$ : INNOVATION DECISION

\begin{tabular}{ccccc}
\hline \hline & \multicolumn{2}{c}{ ML } & \multicolumn{2}{c}{ IV-White } \\
Variable & Parameter & t-Value & Parameter & t-Value \\
\hline Intercept & -1.0186 & -4.14 & -1.0186 & -4.14 \\
HIGH $H_{96}$ & 0.0018 & 2.33 & 0.0018 & 2.33 \\
R\&D & 0.5023 & 2.30 & 0.5023 & 2.30 \\
$M R$ & 0.4450 & 9.65 & 0.4450 & 9.65 \\
PROF & 0.3010 & 4.20 & 0.3010 & 4.20 \\
COOP & 0.4859 & 2.14 & 0.4859 & 2.14 \\
IN $V_{97}$ & $1.35 \mathrm{E}-9$ & 12.23 & $1.35 \mathrm{E}-9$ & 12.23 \\
ICT 95 & 0.3131 & 6.85 & 0.3131 & 6.85 \\
STATE & -0.0992 & -3.69 & -0.0992 & -3.69 \\
DEV & -0.0121 & -0.58 & -0.0121 & -0.58 \\
COMP & 0.1368 & 4.65 & 0.1368 & 4.65 \\
SIZ $E_{50}$ & -0.4281 & -4.39 & -0.4281 & -4.39 \\
SIZE $E_{500}$ & -0.3851 & -4.15 & -0.3851 & -4.15 \\
ONEMAN & -0.0347 & -0.29 & -0.0347 & -0.29 \\
PART & 0.0737 & 0.57 & 0.0737 & 0.57 \\
LIMTD & 0.2320 & 2.08 & 0.2320 & 2.08 \\
CAPT & 0.2135 & 1.52 & 0.2135 & 1.52 \\
PUBL & 0.1174 & 0.74 & 0.1174 & 0.74 \\
\hline ORGA & - & - & - & - \\
\hline Industry & 142.0695 & & 142.0695 \\
Region & 30.7014 & 30.7014 \\
\hline LR-Test & 3624.4956 & 3624.4956 \\
\hline \hline
\end{tabular}


TABLE A.XI

Estimation Results Type II Model $(I N N O \rightarrow O R G A)$ : Organizational Changes

\begin{tabular}{ccccc}
\hline \hline & \multicolumn{2}{c}{ ML } & \multicolumn{2}{c}{ IV-White } \\
Variable & Parameter & t-Value & Parameter & t-Value \\
\hline Intercept & -0.5805 & -2.25 & -0.8670 & -3.35 \\
HIGH96 & 0.0016 & 1.91 & 0.0003 & 0.34 \\
COMP & 0.1019 & 3.10 & 0.0314 & 0.93 \\
DEV $V_{96}$ & 0.0412 & 1.70 & 0.0425 & 1.80 \\
DEV $V_{97}$ & 0.0269 & 1.13 & 0.0353 & 1.49 \\
IN $V_{97}$ & $1.83 \mathrm{E}-9$ & 1.27 & $1.27 \mathrm{E}-09$ & 0.76 \\
ICT 95 & 0.2424 & 4.97 & 0.0670 & 1.25 \\
ICT & 0.4402 & 8.77 & 0.4401 & 8.80 \\
UNION & 0.2404 & 3.76 & 0.2241 & 3.51 \\
SIZE $E_{50}$ & -0.8874 & -8.16 & -0.5832 & -5.06 \\
SIZE & -0.5118 & -5.22 & -0.3204 & -3.11 \\
ONEM $A N$ & -0.4567 & -3.50 & -0.3754 & -2.87 \\
PART & -0.3350 & -2.41 & -0.3463 & -2.52 \\
LIMTD & -0.0822 & -0.67 & -0.1814 & -1.46 \\
CAPT & 0.2369 & 1.57 & 0.1616 & 1.07 \\
PUBL & 0.3815 & 1.79 & 0.2938 & 1.38 \\
\hline INNO & 0.6360 & 13.25 & 1.8777 & 10.89 \\
\hline & LR-Value & LR-Value \\
Industry & 12.1841 & 35.4848 \\
Region & 23.7654 & 19.4927 \\
\hline LR-Test & 9703.0617 & 5165.9397 \\
\hline \hline
\end{tabular}


TABLE A.XII

Estimation Results TyPe II Model $(O R G A \rightarrow I N N O)$ :

Share Equation for High Skilled Employees

\begin{tabular}{ccccc}
\hline \hline & \multicolumn{2}{c}{ OLS } & \multicolumn{2}{c}{ IV-White } \\
Variable & Parameter & t-Value & Parameter & t-Value \\
\hline Intercept & 75.2796 & 18.01 & 74.5356 & 16.88 \\
$I N V_{97} / Y_{97}$ & 0.0023 & 0.01 & -0.1457 & -0.40 \\
$D E V_{97}$ & 0.8410 & 1.87 & 0.5416 & 1.18 \\
$I C T_{97}$ & 4.4372 & 4.12 & 0.3758 & 0.28 \\
$C O M P$ & -0.0024 & -0.00 & -1.1408 & -1.40 \\
STATE $E_{98}$ & -1.2776 & -2.02 & -1.0265 & -1.57 \\
\hline$I N N O$ & 3.1828 & 3.03 & 21.2834 & 4.19 \\
ORGA & 2.2563 & 2.19 & -0.1873 & -0.04 \\
\hline \multicolumn{4}{c}{ F-Value } & F-Value \\
Industry & 19.08 & 18.88 \\
Region & 18.38 & \multicolumn{3}{c}{0.1963} \\
\hline$R_{\text {adj }}^{2}$ & 0.1677 & \\
\hline \hline
\end{tabular}

TABLE A.XIII

Estimation Results Type II Model $(O R G A \rightarrow I N N O)$ :

Share Equation for Low Skilled Employees

\begin{tabular}{ccccc}
\hline \hline & \multicolumn{2}{c}{ OLS } & \multicolumn{2}{c}{ IV-White } \\
Variable & Parameter & t-Value & Parameter & t-Value \\
\hline Intercept & 17.3708 & 4.16 & 17.2763 & 3.90 \\
$I N V_{97} / Y_{97}$ & -0.1142 & -0.34 & 0.1296 & 0.04 \\
$D E V$ & -0.7244 & -1.61 & -0.6591 & -1.45 \\
$I C T_{97}$ & -3.3870 & -3.15 & -1.0882 & -0.80 \\
$C O M P$ & 0.0514 & 0.08 & 0.8496 & 1.02 \\
STATE $E_{98}$ & 1.6038 & 2.54 & 1.4587 & 2.22 \\
\hline INNO & -2.8812 & -2.75 & -19.5096 & -3.95 \\
ORGA & -2.2677 & -2.21 & 5.2894 & 1.26 \\
\hline \multicolumn{5}{c}{ F-Value } \\
Industry & 21.74 & F-Value \\
Region & 21.90 & 21.41 \\
\hline$R_{\text {adj }}^{2}$ & 0.1893 & 22.53 \\
\hline \hline
\end{tabular}


TABLE A.XIV

Estimation Results Type II Model $(O R G A \rightarrow I N N O)$ : INNOVATION DECISION

\begin{tabular}{ccccc}
\hline \hline & \multicolumn{2}{c}{ ML } & \multicolumn{2}{c}{ IV-White } \\
Variable & Parameter & t-Value & Parameter & t-Value \\
\hline Intercept & -1.2680 & -5.06 & -1.7469 & -5.98 \\
HIGH $H_{96}$ & 0.0015 & 1.92 & 0.0003 & 0.38 \\
R\&D & 0.6502 & 2.98 & 0.5489 & 2.44 \\
$M R$ & 0.3591 & 7.60 & 0.3910 & 8.19 \\
PROF & 0.1891 & 2.60 & 0.2742 & 3.72 \\
COOP & 0.3069 & 1.35 & 0.4068 & 1.74 \\
IN $V_{97}$ & $1.19 \mathrm{E}-9$ & 1.09 & $1.08 \mathrm{E}-09$ & 0.92 \\
ICT 95 & 0.2532 & 5.43 & 0.0847 & 1.46 \\
STATE & -0.1036 & -3.80 & -0.1064 & -3.86 \\
DEV $V_{97}$ & -0.0192 & -0.91 & -0.0328 & -1.52 \\
COMP & 0.1262 & 4.23 & 0.0557 & 1.66 \\
SIZ $E_{50}$ & -0.2418 & -2.42 & 0.1928 & 1.34 \\
SIZE $E_{500}$ & -0.3097 & -3.29 & -0.1050 & -0.97 \\
ONEMAN & 0.0433 & 0.36 & 0.2014 & 1.43 \\
PART & 0.1360 & 1.04 & 0.2045 & 1.41 \\
LIMTD & 0.2362 & 2.07 & 0.2336 & 1.82 \\
CAPT & 0.1659 & 1.17 & 0.0816 & 0.52 \\
PUBL & 0.0782 & 0.49 & -0.0107 & -0.05 \\
\hline ORGA & 0.5967 & 12.17 & 1.6293 & 6.36 \\
\hline & LR-Value & LR-Value \\
Industry & 137.2174 & 23.3733 \\
Region & 24.7570 & 29.3530 \\
\hline LR-Test & 8121.8093 & 5020.4088 \\
\hline \hline
\end{tabular}


TABLE A.XV

Estimation Results TyPe II Model $(O R G A \rightarrow I N N O)$ : Organizational Changes

\begin{tabular}{ccccc}
\hline \hline & \multicolumn{2}{c}{ ML } & \multicolumn{2}{c}{ IV-White } \\
Variable & Parameter & t-Value & Parameter & t-Value \\
\hline Intercept & -0.5295 & -2.09 & -0.5295 & -2.09 \\
HIGH96 & 0.0021 & 2.56 & 0.0021 & 2.56 \\
COMP & 0.1287 & 4.00 & 0.1287 & 4.00 \\
DEV $V_{96}$ & 0.0403 & 1.70 & 0.0403 & 1.70 \\
DEV $V_{97}$ & 0.0225 & 0.97 & 0.0225 & 0.97 \\
IN $V_{97}$ & $1.98 \mathrm{E}-09$ & 1.42 & $1.98 \mathrm{E}-09$ & 1.42 \\
ICT $T_{95}$ & 0.3000 & 6.31 & 0.3000 & 6.31 \\
ICT 97 & 0.5059 & 10.36 & 0.5059 & 10.36 \\
UNION & 0.2649 & 4.23 & 0.2649 & 4.23 \\
SIZE $E_{50}$ & -0.9361 & -8.88 & -0.9361 & -8.88 \\
SIZE & -0.5665 & -5.97 & -0.5665 & -5.97 \\
ONEM $A N$ & -0.4322 & -3.40 & -0.4322 & -3.40 \\
PART & -0.2828 & -2.09 & -0.2828 & -2.09 \\
LIMTD & 0.0002 & 0.00 & 0.0002 & 0.00 \\
CAPT & 0.3173 & 2.16 & 0.3173 & 2.16 \\
PUBL & 0.3752 & 1.84 & 0.3752 & 1.84 \\
\hline INNO & - & - & - & - \\
\hline & LR-Value & LR-Value \\
Industry & 23.3733 & 23.3733 \\
Region & 29.3530 & 29.3530 \\
\hline LR-Test & 5020.4088 & 5020.4088 \\
\hline \hline
\end{tabular}


TABLE A.XVI

DESCRIPTIVE RESULTS:

Pearson Correlation Coefficient Between Different Forms of InNovation (SignificAnCE LEVEL in PARENTheSes)

\begin{tabular}{cccc}
\hline \hline & Improvement & Incremental & Radical \\
\hline \multirow{2}{*}{ Improvement } & 1.00 & 0.44 & 0.29 \\
& $(-)$ & $(<.001)$ & $(<.001)$ \\
Incremental & & 1.00 & 0.24 \\
& & $(-)$ & $(<.001)$ \\
Radical & & & 1.00 \\
& & & $(-)$ \\
\hline \hline
\end{tabular}

TABLE A.XVII

DesCRIPTIVE REsults:

Pearson Correlation Coefficient Between Different Organizational Changes (Significance Level in Brackets)

\begin{tabular}{ccccc}
\hline \hline & Reorganization & Decentralization & Responsibility & Own Costing \\
\hline \multirow{2}{*}{ Reorganization } & 1.00 & 0.44 & 0.36 & 0.35 \\
& $(-)$ & $(<.001)$ & $(<.001)$ & $(<.001)$ \\
Decentralization & & 1.00 & 0.42 & 0.34 \\
& & $(-)$ & $(<.001)$ & $(<.001)$ \\
Responsibility & & 1.00 & 0.29 \\
& & $(-)$ & $(<.001)$ \\
Own Costing & & & 1.00 \\
& & & \\
\hline \hline
\end{tabular}

TABLE A.XVIII

DESCRIPTIVE RESULTS:

Percentage of Establishments Falling in each Category

\begin{tabular}{llrl}
\hline \hline & & \multicolumn{2}{c}{ Organizational Change } \\
& & Yes & No \\
\hline \multirow{2}{*}{ Innovation Decision } & Yes & $38 \%$ & $15 \%$ \\
& No & $15 \%$ & $31 \%$ \\
\hline \hline
\end{tabular}




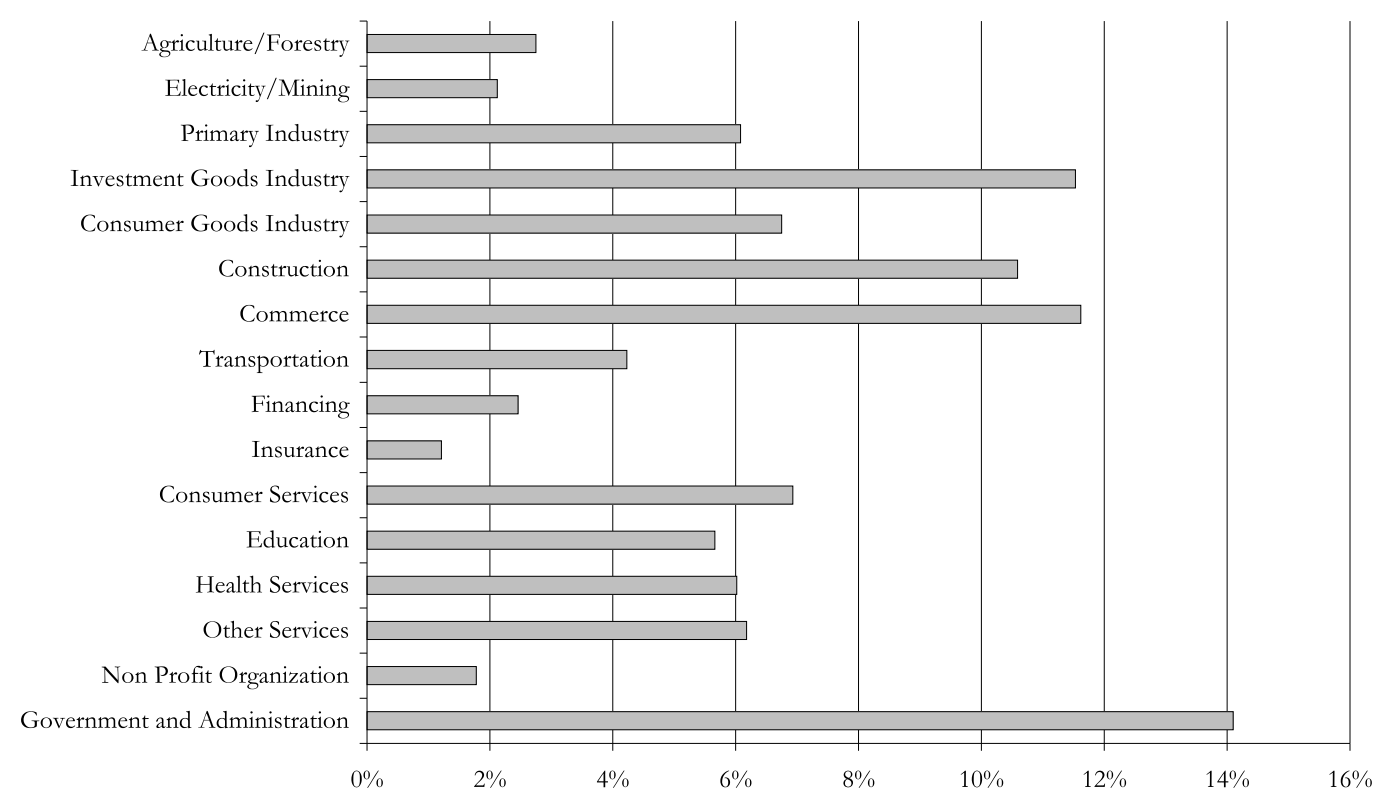

Figure A.I: Affiliation to Industrial Sectors of Establishments that PARTICIPATED IN 1998 AND 1996 AT the IAB PANEL

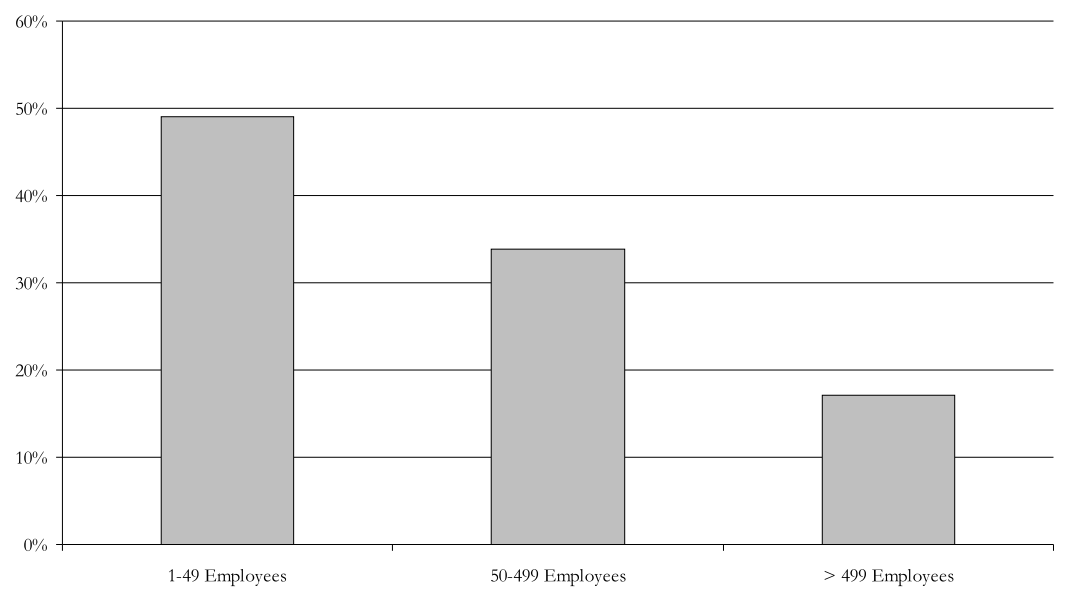

Figure A.II: Size Class of Establishments that Participated in 1998 and 1996 AT THE IAB PANEL 


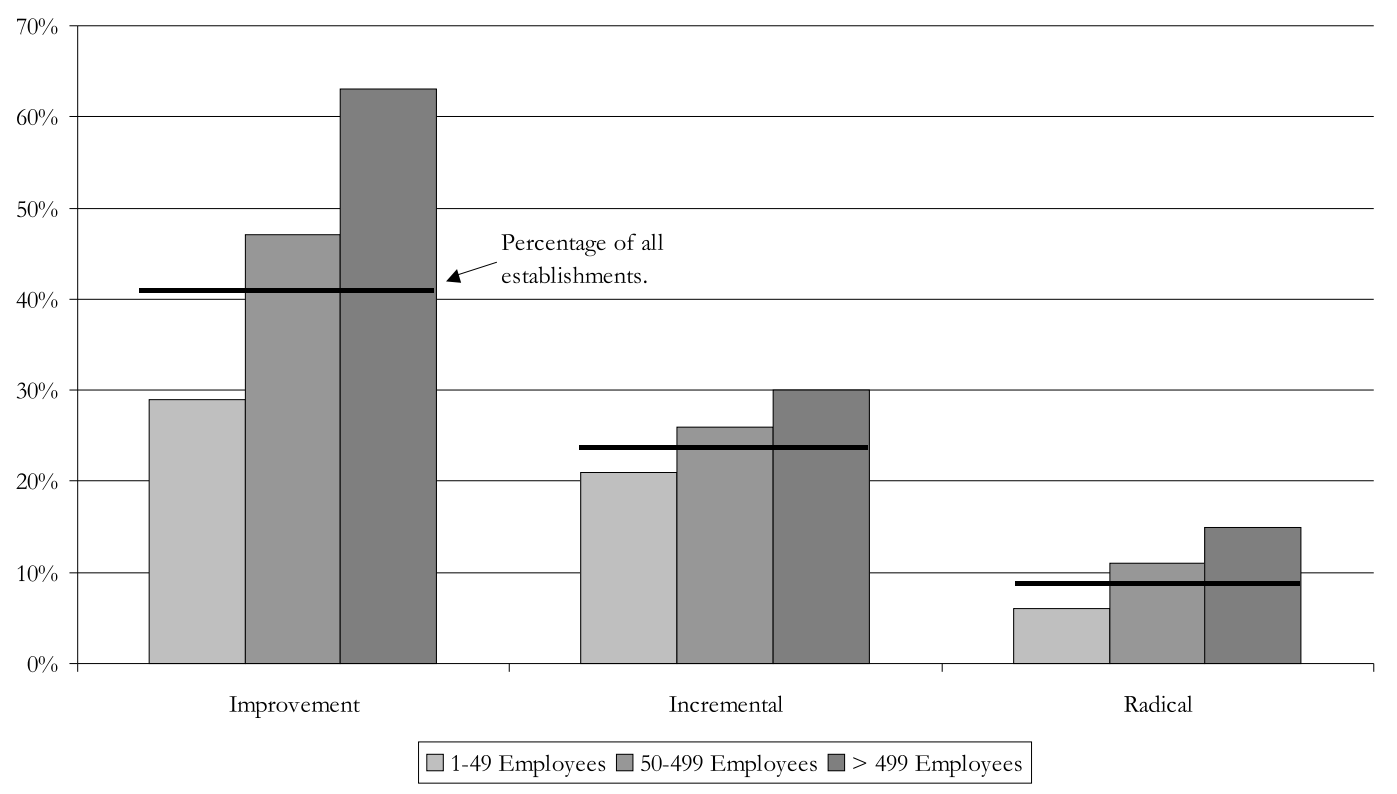

Figure A.III: Innovation Decision with Regard to the Size Class of the ESTABLISHMENTS

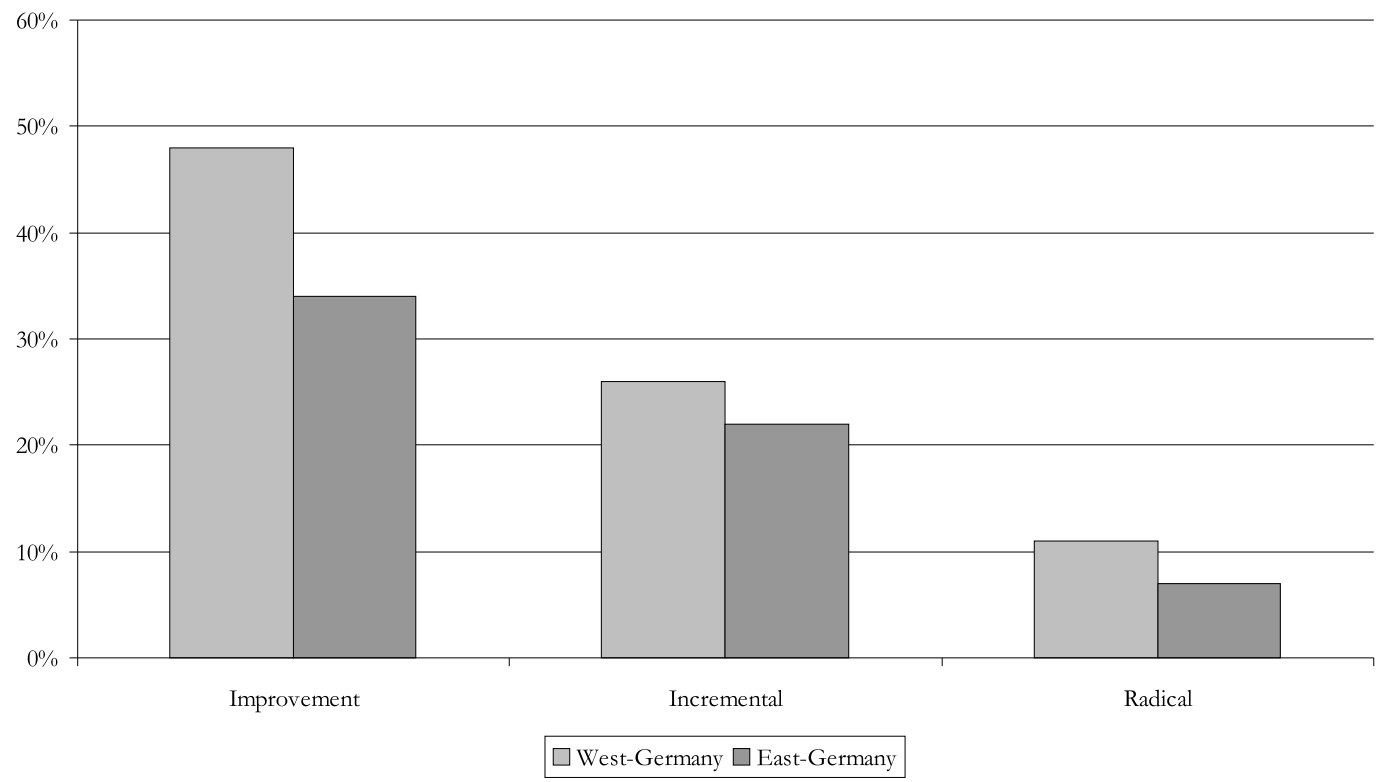

Figure A.IV: InNovation Decision for West- AND EAst-German ESTABLISHMENTS 


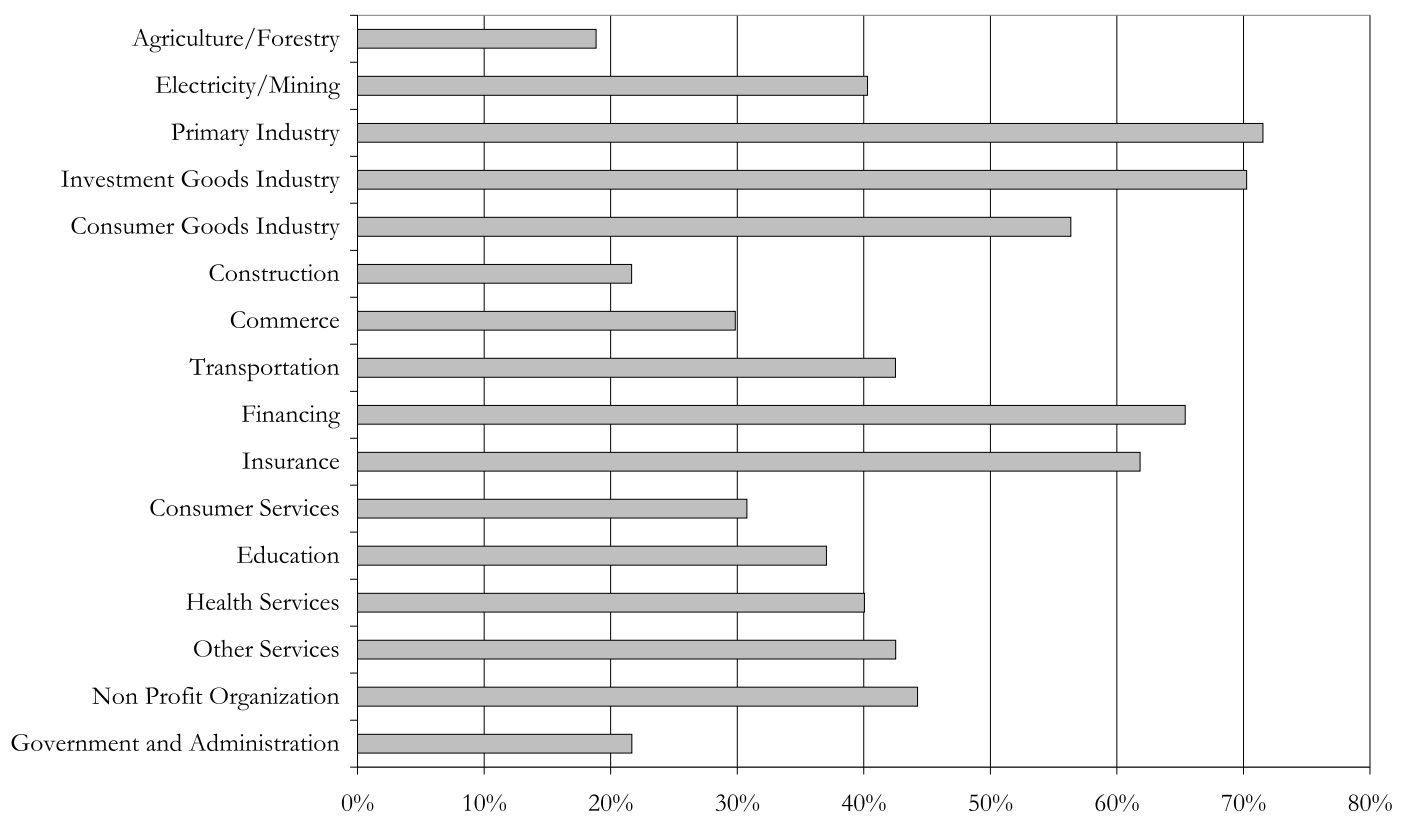

Figure A.V: Improvement of Existing Products and Services with Regard to the Industrial AfFiliation of the Establishments

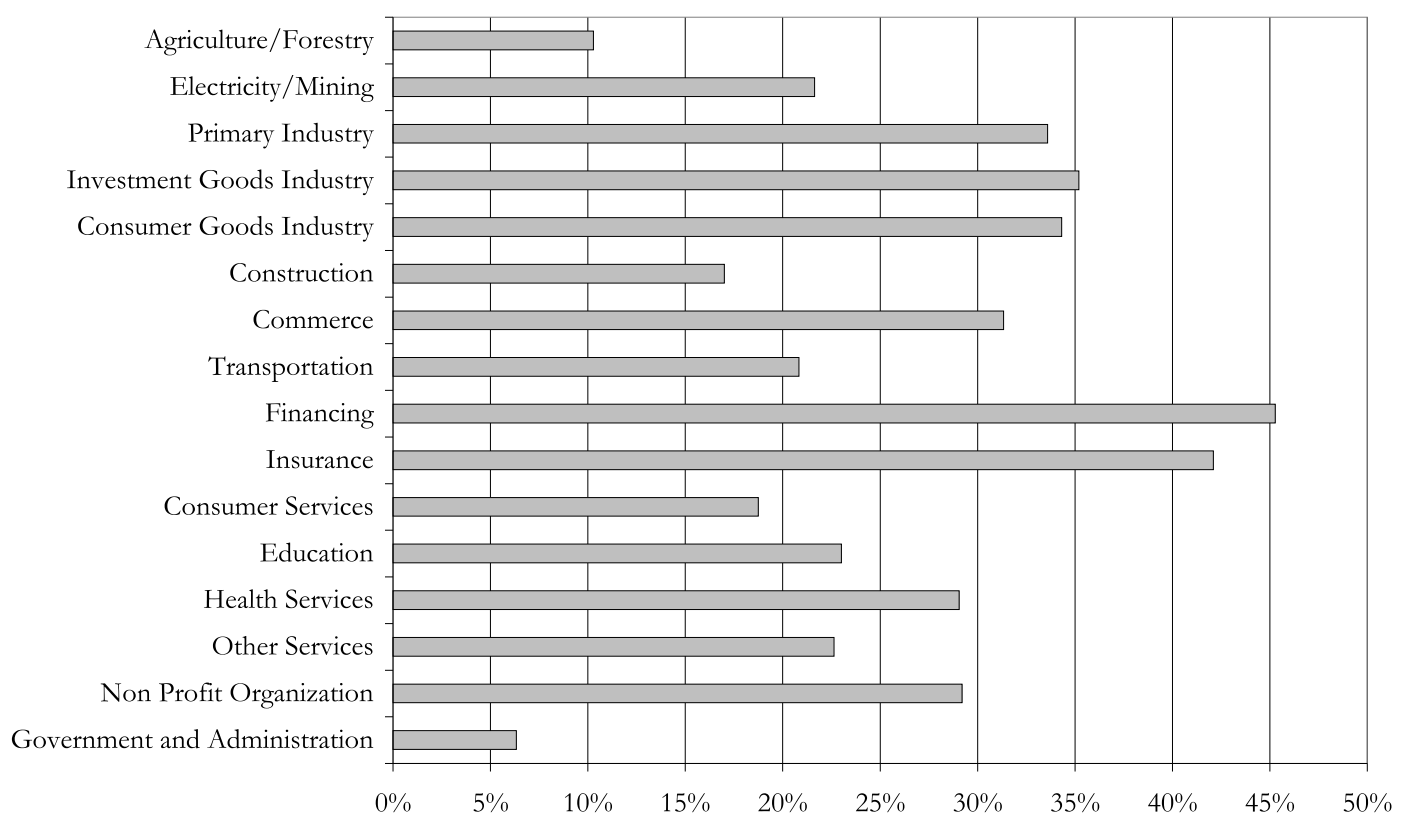

Figure A.VI: Introduction of Products and Services that are New for the Own Establishment with Regard to the Industrial Affiliation of the ESTABLISHMENTS 


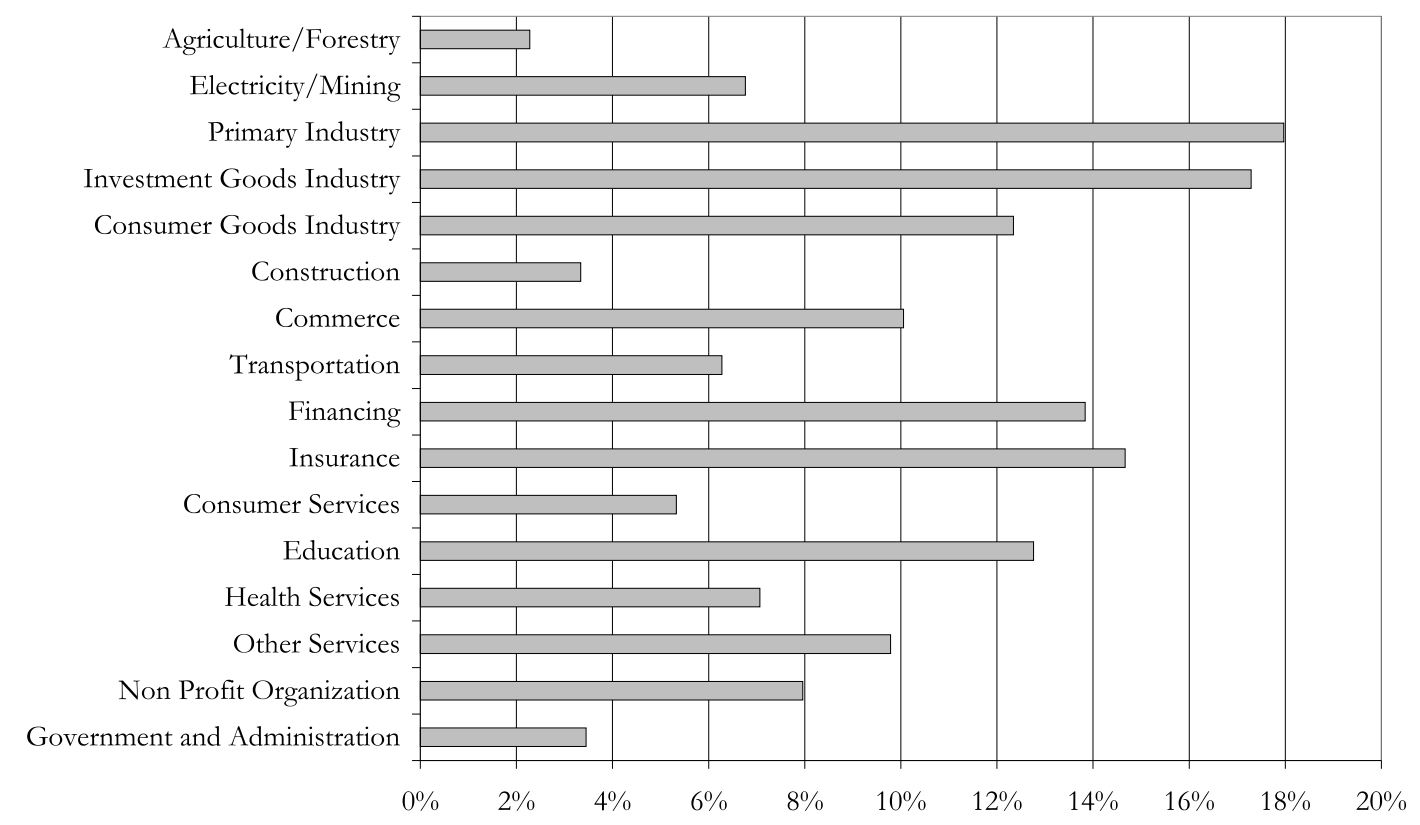

Figure A.ViI: Introduction of Products and Services that are New for the Market with Regard to the Industrial Affiliation of the ESTABLISHMENTS

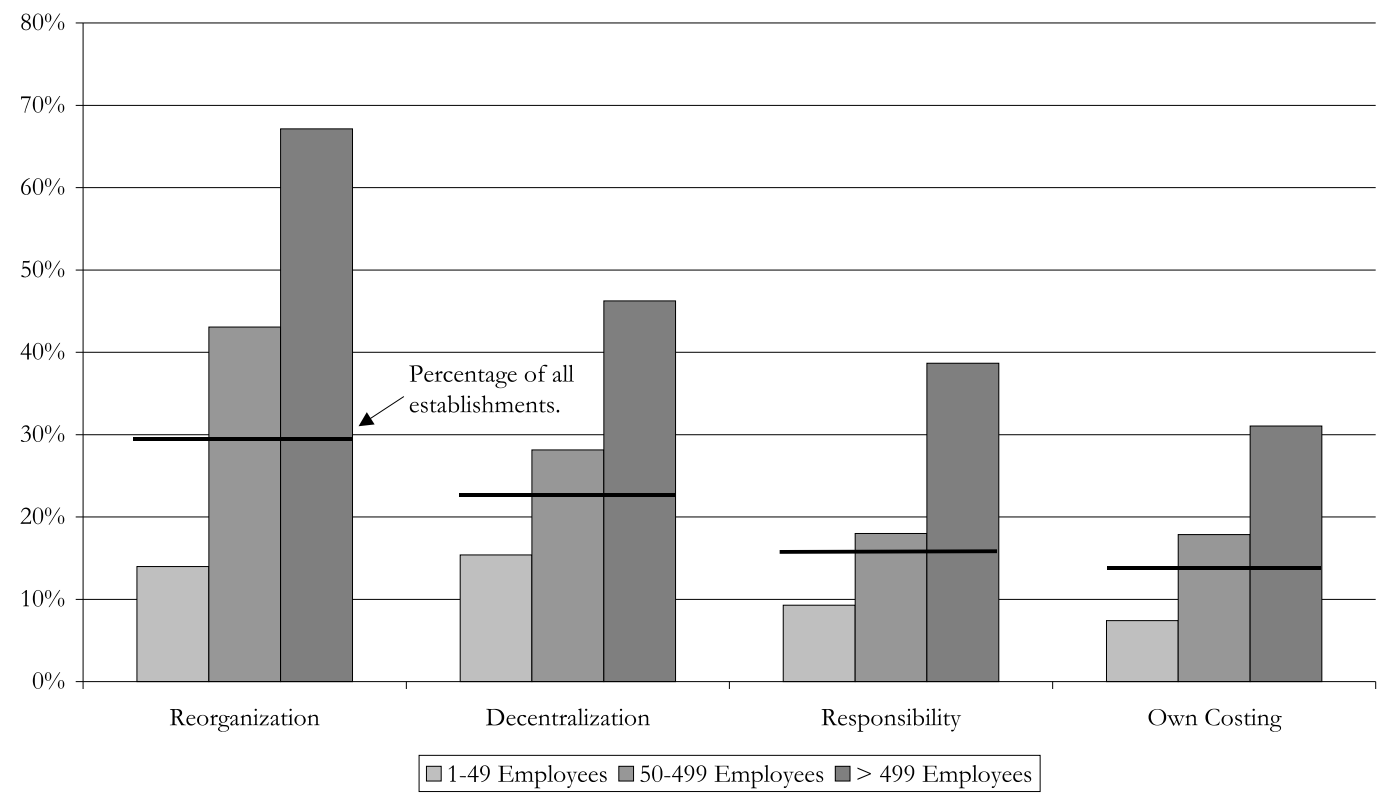

Figure A.ViII: Organizational Changes with Regard to the Size Class of THE EstABLISHMENTS 


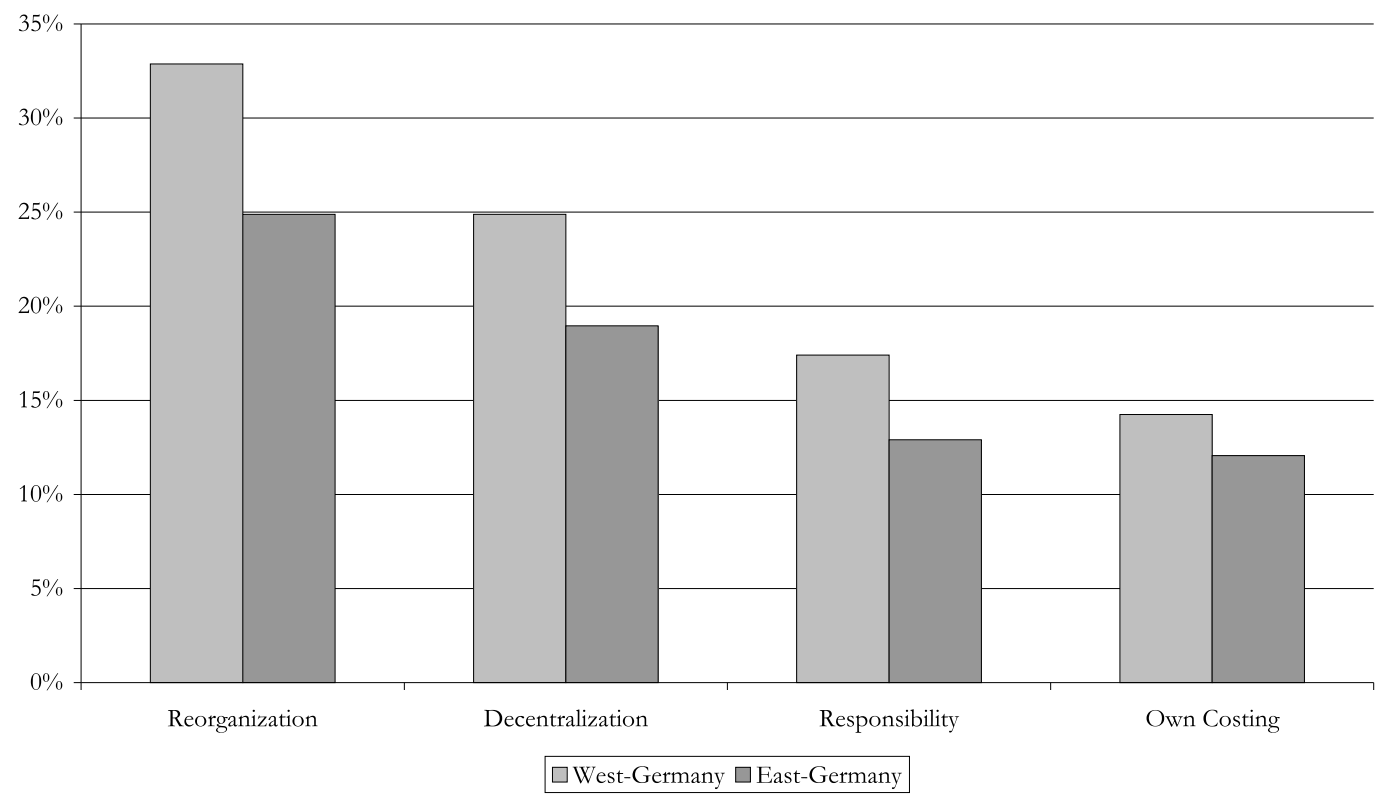

Figure A.IX: Organizational Changes for West- and East-German ESTABLISHMENTS

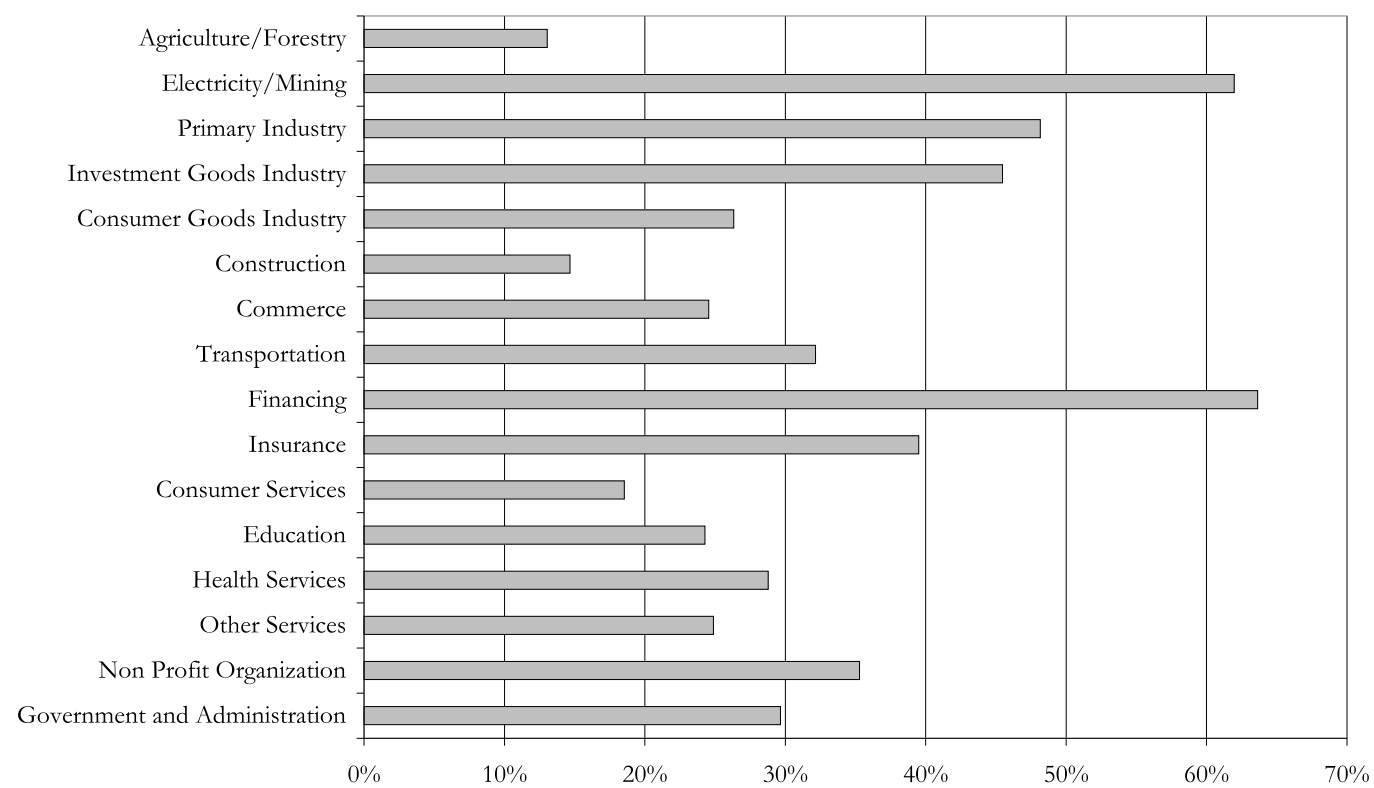

Figure A.X: Reorganization of Departments and Functional Areas with REgARD to the INDUStRIAL AfFILIATION OF THE Establishments 


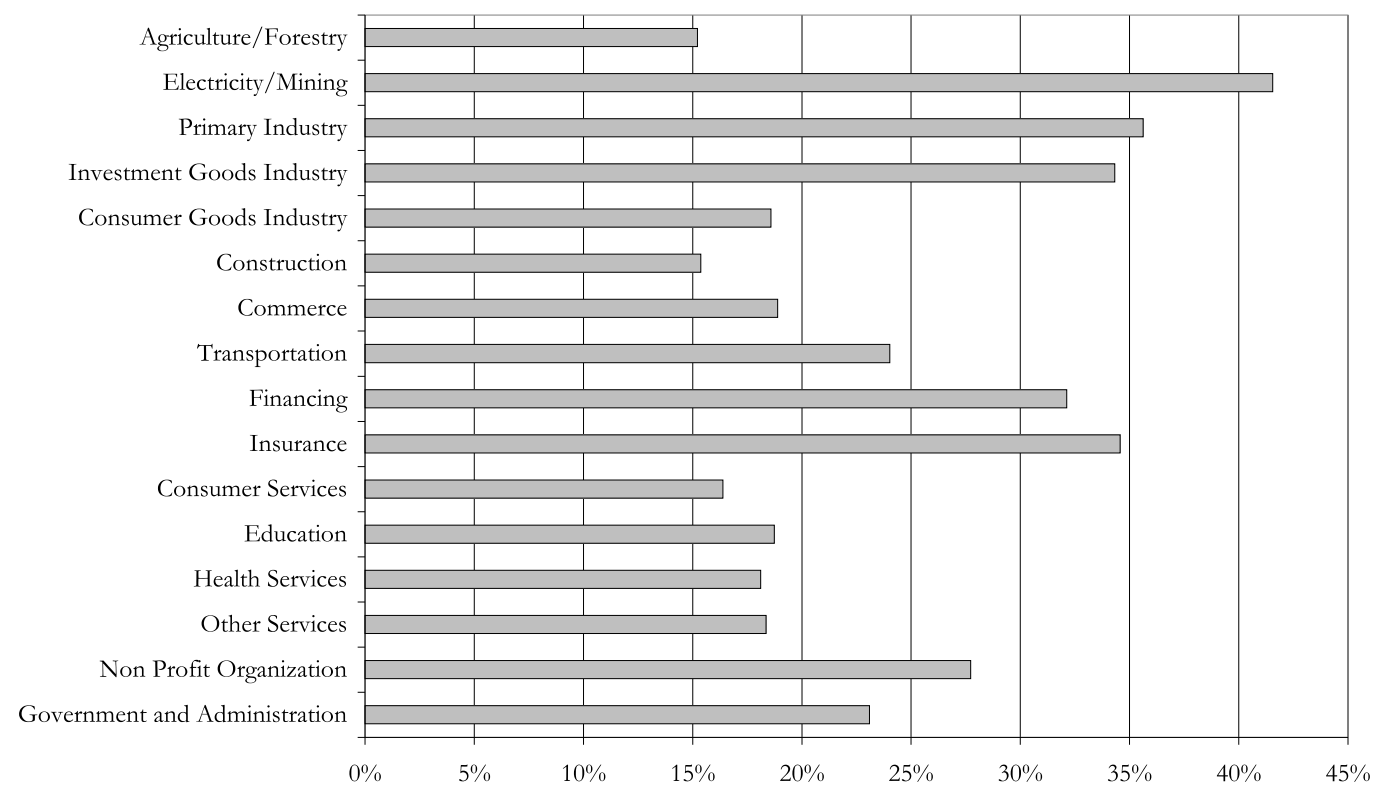

Figure A.Xi: Decentralization of Responsibilities and Decision-Authority With Regard to the Industrial AfFiliation of the Establishments

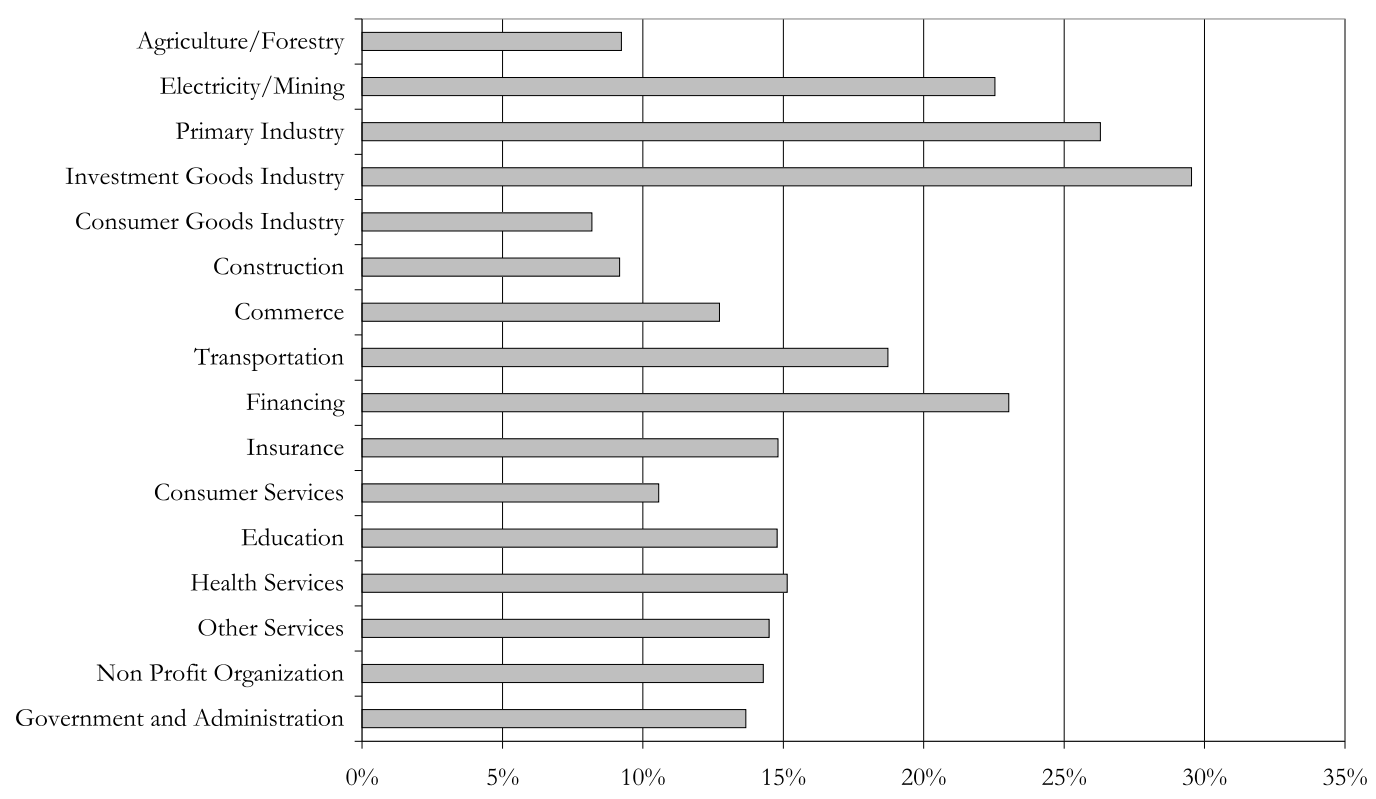

Figure A.XiI: Introduction of Group-WorkPlaces With OWN RESPONSIBILITIES With REgaRd to the INDUStRial AfFiliation of the ESTABLISHMENTS 


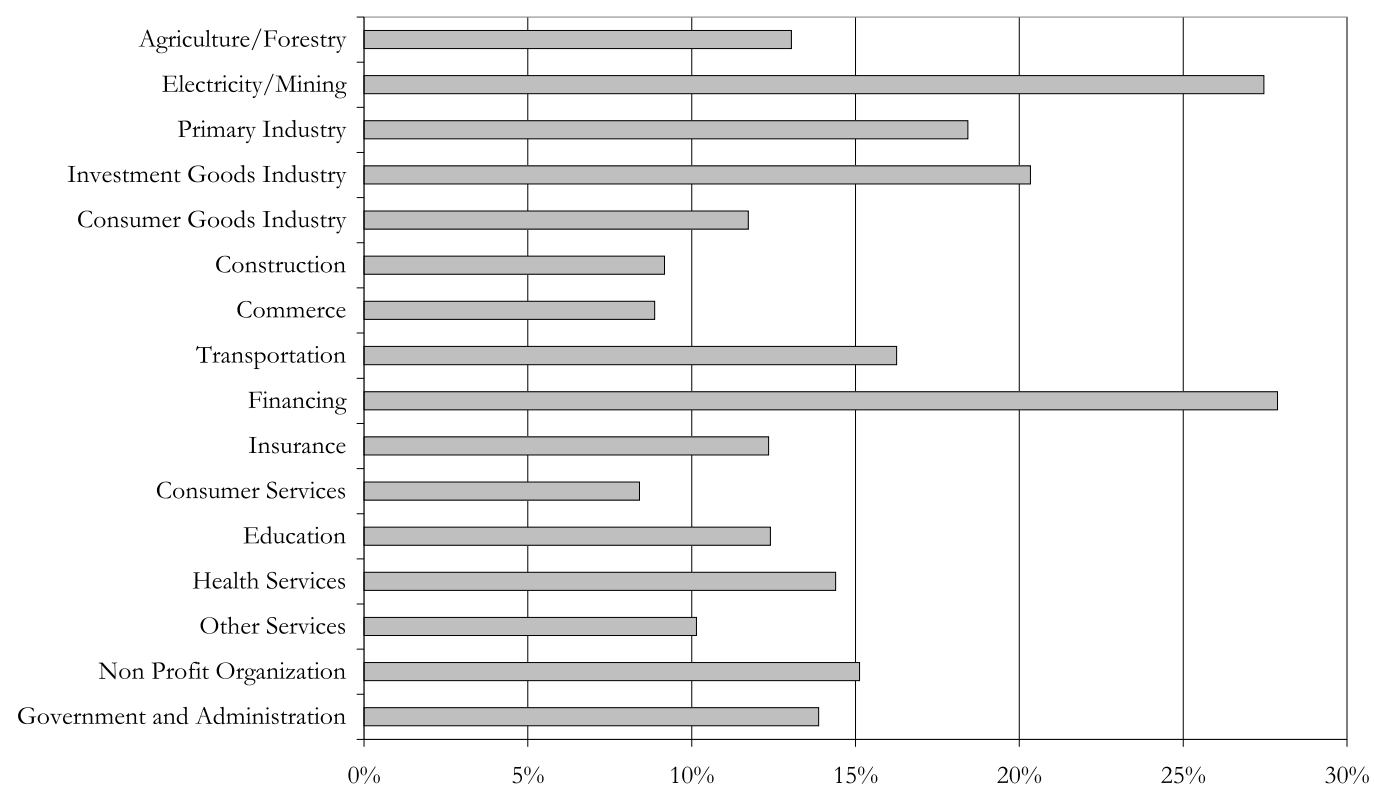

Figure A.XiII: Introduction of Units with Own Costing and Result

Calculation with Regard to the Industrial Affiliation of the ESTABLISHMENTS 


\section{REFERENCES}

AmemiYA, T. (1974): "Multivariate Regression and Simultaneous Equation Models when the Dependent Variables are Truncated Normal," Econometrica, 42(6), 9991012 .

(1979): "The Estimation of a Simulataneous-Equation Tobit-Model," International Economic Review, 20(1), 999-1012.

Autor, D. H., L. F. Katz, And A. B. Krueger (1998): "Computing Inequality: Have Computers Changed the Labor Market," Quarterly Journal of Economics, pp. 1169-1213.

Bartel, A. P., And F. R. Lichtenberg (1987): "The Comparative Advantage of Educated Workers in Implementing New Technology," The Review of Economics and Statistics, 69(1).

Bell, B. D. (1996): "Skill-Biased Technical Change and Wages: Evidence from a Longitudinal Data Set," Discussion paper, Institute of Economics \& Statistics, University of Oxford.

Bellmann, L. (1997): "Das Betriebspanel des IAB," in Wirtschafts- und sozialwissenschaftliche Panel-Studien, ed. by R. Hujer, U. Rendtel, and G. Wagner, pp. 169182. Vandenhoeck und Ruprecht.

Bellmann, L., AND A. Kölling (2000): "The IAB-Establishment Panel as an Instrument for Scientific Research," Paper prepared for the Ninth International Conference on Panel Data, June 22th - 23th, Geneva, Switzerland.

Berman, E., B. J., AND Z. Griliches (1994): "Changes in the Demand for Skilled Labor within U.S. Manufacturing: Evidence from the Annual Survey of Manufactures," Quarterly Journal of Economics, pp. 367-397.

Berman, E., J. Bound, And S. Machin (1998): "Implications of Skill-Biased Technological Change: International Evidence," Quarterly Journal of Economics, pp. 12451279 .

Blundell, R. W., AND R. J. Smith (1993): "Simultaneous Microeconometric Models with Censored or Qualitative Dependent Variables," Handbook of Statistics, 11, 117143.

(1994): "Coherency and Estimation in Simultaneous Models with Censored or Qualitative Dependent Variables," Journal of Econometrics, 64, 355-373.

Bresnahan, T. F., E. Brynjolfsson, and L. Hitt (1999): "Information Technology Workplace Organization, and the Demand for Skilled Labor: Firm-Level Evidence," Working Paper 7136, NBER, Cambridge.

Browning, M. (1992): "Children and Household Economc Behavior," Journal of Economic Literature, XXX, 1434-1475.

Butler, J. S., AND G. PiCone (1999): "Logically Inconsistent Limited Dependent Variables Models," in Generalized Method of Moments Estimation, ed. by L. Matyas. Cambridge University Press.

Caroli, E., AND J. V. ReEnEN (2001): "Skill Biased Organizational Change? Evidence from a Panel of British and French Establishments," Research unit working paper no. 00-06, LEA-INRA.

Crepon, B., E. Duguet, And J. Mairesse (1998): "Research, Innovation, and Productivity: An Econometric Analysis at the Firm Level," Working Paper 6696, National Bureau of Economic Research, NBER, Cambridge. 
Davidson, R., And J. G. MacKinnon (1981): "Several Tests for Model Specification in the Presence of Alternative Hypotheses," Econometrica, 49(3), 781-793.

FALK, M., AND K. SEIM (1999): "The Impact of Information Technology on HighSkilled Labour in Services: Evidence from Firm Level Panel Data," Discussion paper no. 58, ZEW.

Hamermesh, D. S. (1986): "The Demand for Labor in the Long Run," in Handbook of Labor Economics, ed. by O. Ashenfelter. Elsevier Science, Amsterdam.

(1993): Labor Demand. Princeton University Press.

Katsoulacos, Y. S. (1986): The Employment Effect of Technical Change. University of Nebraska Press.

KÖLling, A. (2000): “The IAB-Establishment Panel," Schmollers Jahrbuch, 120, 291300.

Krueger, A. B. (1993): "How Computers Have Changed the Wage Structure: Evidence From Microdata, 1984-1989," Quarterly Journal of Economics, 108(1), 33-60.

Krugman, P. (1994): "Past and Prospective Causes of High Unemployment," in Reducing Unemployment: Current Issues and Policy Options. Federal Reserve Bank of Kansas City.

LEE, L.-F. (1978): "Unionism and Wage Rates: A Simultaneous Equations Model with Qualitative and Limited Dependent Variables," International Economic Review, 19(2), 415-433.

(1990): "Simultaneous Equations Models with Discrete Endogenous Variables," Discussion paper.

LI, K. (1998): "Bayesian Inference in a Simultaneous Equation Model with Limited Dependent Variables," Journal of Econometrics, 85, 387-400.

Lundvall, B.-A., AND F. S. Kristensen (1997): "Organisational Change, Innovation and Human Ressource Development as a Response to Increased Competition," Working paper, Danish Research Unity for Industrial Dynamics.

Machin, S., AND S. WADHWANI (1991): "The Effects of Unions on Organisational Change and Employment," The Economic Journal, 101(407), 835-854.

Nelson, F., AND L. Olson (1978): "Specification and Estimation of a SimultaneousEquation Model with Limited Dependent Variables," International Economic Review, 19(3), 695-709.

Pohlmeier, W. (1989): Simultane Probit- und Tobitmodelle. Springer.

Ransom, M. R. (1987): "An Empirical Model of Discrete and Continuous Choice in Family Labor Supply," The Review of Economics and Statistics, 69(3), 465-472.

Schmid T, P. (1978): "Estimation of a Simultaneous Equations Model with Jointly Dependent Continous and Qualitative Variables: The Union-Earnings Question Revisted," International Economic Review, 19(2), 453-465.

(1990): "Constraints on the Parameters in Simultaneous Tobit and Probit Model," in Structural Analysis of Discrete Data with Econometric Applications. The MIT Press.

SNower, D. J. (1999): "Causes of Changing Earnings Inequality," Discussion paper no. 29, IZA. 
Waldman, D. M. (1981): "An Economic Interpretation of Parameter Constraints in a Simultaneous-Equations Model with Limited Dependent Variables," International Economic Review, 22(3), 730-739.

White, H. (1982): "Maximum Likelihood Estimation of Misspecified Models," Econometrica, 50(1), 1-26.

WiLde, J. (1999): Gemischte simultane Modelle für Querschnittsdaten. Peter Lang, Frankfurt/M., Berlin u.a. 